\title{
The initial fabric of undisturbed and reconstituted fluvial sand
}

\author{
V. SANTIAGO QUINTEROS* and J. ANTONIO H. CARRARO $\dagger$
}

\begin{abstract}
High-quality undisturbed samples of fluvial sand were obtained from the field using the ground freezing technique. In the laboratory, the in situ void ratio of these high-quality undisturbed frozen samples was replicated using four different reconstitution methods: dry deposition, moist tamping, water sedimentation (by spooning) and slurry deposition. The initial fabric of the specimens was evaluated using X-ray micro-computed tomography and advanced image analysis. Initial fabric features were assessed in terms of the particle orientation, anisotropy, void ratio distribution and particle sizes within the specimens. Fabric analysis results suggest that none of the laboratory reconstitution techniques used captures the true three-dimensional initial fabric of undisturbed fluvial sand. However, the slurry deposition method managed to reproduce the inherent particle orientation, anisotropy and the variations of void ratio and particle sizes of the undisturbed fluvial sand. This observation explains why previous rigorous studies on the macro-mechanical behaviour of sands deposited under water have systematically demonstrated that slurry deposition is the most suitable method to reconstitute in the laboratory natural sands deposited under water. This has major implications for geotechnical testing and analyses of liquefaction of sands deposited under water such as fluvial, offshore and tailings sands.
\end{abstract}

KEYWORDS: anisotropy; fabric/structure of soils; ground freezing; laboratory tests; sampling

\section{INTRODUCTION}

Granular soils are complex assemblies of discrete particles with a certain fabric. Fabric can be defined as the particle sizes, shapes and their distribution, along with the arrangement of grains and their contacts in a given soil (Mitchell \& Soga, 2005). Initial fabric controls key features of a soil's mechanical response such as its small-strain stiffness, undrained instability, phase transformation and peak strength, as well as the soil's undrained cyclic strength (Wanatowski \& Chu, 2008; Shi et al., 2020). Sands are very difficult to sample in an undisturbed state so that their initial fabric remains intact. State-of-the-practice sand sampling techniques induce sample disturbance. As a result, sands are commonly reconstituted in the laboratory to target void ratios empirically derived from in situ tests, such as the cone penetration test (CPT). However, as has been known for about 50 years, every reconstitution technique imposes a different initial fabric and, consequently, a different stressstrain behaviour on reconstituted sands (Oda, 1972; Ladd, 1974; Arthur \& Phillips, 1975; Ladd et al., 1977; Mulilis et al., 1977; Silver et al., 1980; Miura \& Toki, 1982; Kuo \& Frost, 1996; Vaid \& Sivathayalan, 2000; Yamamuro \& Wood, 2004; Madhusudhan \& Baudet, 2014). It has been claimed that high-quality undisturbed samples of sands can be obtained either by improving sampling techniques or by stabilising a portion of the soil in situ. Allegedly improved sampling techniques include block sampling (on cemented locked sands with fines), the Bishop sampler (Bishop, 1948) and the Gel-Push sampler (Mori \& Sakai, 2016). However,

Manuscript received 19 April 2020; revised manuscript accepted 18 May 2021. Published online ahead of print 3 November 2021.

Discussion on this paper closes on 1 May 2023, for further details see p. ii.

Published with permission by the ICE under the CC-BY 4.0 license. (http://creativecommons.org/licenses/by/4.0/)

* Advanced Modelling, Norwegian Geotechnical Institute, Oslo, Norway; also Department of Civil and Environmental Engineering, Imperial College London, UK (Orcid:0000-0002-4895-1580).

$\dagger$ Department of Civil and Environmental Engineering, Imperial

College London, UK (Orcid:0000-0002-4648-3859). these sampling methods may cause either densification or loosening of sand samples, depending on the sand's initial fabric. Moreover, disturbances during sample transportation, handling, extrusion and specimen preparation may change the initial sand fabric before a specimen is tested in the laboratory. To avoid disturbances, stabilisation methods such as soil impregnation or freezing have been proposed. Soil impregnation using agar, agarose and Elmer's glue has been used in research studies (e.g. Frost, 1989; Schneider et al., 1989; Sutterer et al., 1996; Yang, 2002; Evans, 2005), but in situ impregnation still has not found its way into practice. Nonetheless, any substance introduced into the soil voids must also be somehow removed prior to testing, which requires special procedures and care. Ground freezing is considered to be the most suitable technique to obtain undisturbed samples of non-frost-susceptible sands, although the costs are restrictively high. Sand sampling by ground freezing has been successfully used in Japan, Canada, the United States of America and Italy (Yoshimi et al., 1977, 1984; Sego et al., 1994; Robertson et al., 2000; Ghionna et al., 2001). Liquid nitrogen, brine, or ethanol mixed with ice are feasible options for freezing the ground (Stoss \& Valk, 1979; Andersland \& Ladanyi, 1994).

Very few studies have compared the macroscopic stressstrain behaviour of high-quality undisturbed fluvial sands with the behaviour of their reconstituted counterparts using more than one specimen reconstitution method. Vaid et al. (1999) compared the stress-strain behaviour of frozen and thawed loose sand specimens against specimens reconstituted by moist tamping (MT) (without undercompaction), water pluviation (WP) and air pluviation. Based on undrained simple shear, triaxial compression and extension tests of frozen and reconstituted sand at effective confining stresses between 50 and $500 \mathrm{kPa}$, Vaid et al. (1999) argued that the WP technique seems to 'closely duplicate' the fabric of natural fluvial sand and hydraulic fill. This statement was made without a comprehensive micro-computed tomography $(\mu \mathrm{CT})$ image-based analysis of the initial fabric of the materials tested, as $\mu \mathrm{CT}$ technology was not available at the time, to the required extent. Huang \& Huang (2007) obtained dense to very dense samples of alluvial sands and 




silts (fines contents ranging from 18 to $89 \%$ ) using the Laval sampler (La Rochelle et al., 1981) and frozen above the ground following recommendations by Konrad et al. (1995). They conducted isotropically consolidated, undrained monotonic triaxial tests with $p^{\prime}=100 \mathrm{kPa}$ and concluded that none of the reconstitution techniques they used (MT without undercompaction and WP) replicates the macroscopic stressstrain behaviour of undisturbed alluvial sands with fines. Vaid et al. (1999) observed contractive behaviour of loose MT specimens under undrained triaxial compression, while Huang \& Huang (2007) did not observe any definitive trend for denser MT soil, arguing that fines content and mineralogy may also play a role.

A more recent research study (Fonseca et al., 2013) analysed and compared the microscopic initial fabric of block samples of a marine-deposited overconsolidated 'locked' sand from Reigate, UK, against that of reconstituted specimens using dry pouring and tamping. To preserve the initial fabric, epoxy resin (EPO-TEK 301 by Epoxy Technology Inc., Billerica, USA) was injected both into the block and reconstituted specimens. Void ratio changes due to epoxy impregnation were measured using local displacement transducers and reported as negligible (on average, $\Delta e=0 \cdot 001$ ), although axial and radial strain values were not reported. $\mu \mathrm{CT}$ images were then obtained for the impregnated block and reconstituted specimens and directional fabric descriptors from image analysis were used to compare the fabric of the different specimens. The voids and contacts between particles of the block samples were quite different from those obtained for the reconstituted specimens. A different macroscopic behaviour was also observed when the specimens were tested in drained triaxial compression with $p^{\prime}$ mainly at $300 \mathrm{kPa}$.

Based on this limited set of available studies, it may be argued that WP replicates the macro stress-strain behaviour of a natural fluvial sand (Vaid et al., 1999). Dry deposition mimics the microscopic particle orientation (but not the contacts) of a locked sand but does not replicate its macro response (Fonseca et al., 2013). Moist tamping does not replicate the macro response of fluvial and alluvial sands (Vaid et al., 1999; Huang \& Huang, 2007). A summary of these studies is provided in Table 1 . No previous comprehensive studies on undisturbed specimens of fluvial sands and their reconstituted counterparts appear to have been carried out to date, particularly when the initial fabric of the sand has been systematically quantified and compared.

The present study helps to elucidate, for the first time, which laboratory reconstitution method is best suited to replicate the initial fabric of natural fluvial sand. The study's novelty relies on the combined use of state-of-the-art undisturbed soil sampling by way of ground freezing along with X-ray $\mu \mathrm{CT}$ and image analysis of the $\mu \mathrm{CT}$ data to quantify soil fabric descriptors. The initial fabric of undisturbed sand is then compared to the initial fabric of specimens reconstituted in the laboratory using four methods: MT, dry deposition (DD), water sedimentation by spooning (WS) and slurry deposition (SD). This allowed direct comparison among various methods and the determination of the laboratory reconstitution method that best replicates the initial fabric, quantified in terms of particle orientation, anisotropy and the variations of void ratio and particle sizes, of the undisturbed fluvial sand tested.

\section{RESEARCH METHODOLOGY}

Geology and description of the research site

The undisturbed sand tested was obtained from a post-glacial fluvial deposit named Øysand, located about $15 \mathrm{~km}$ southwest of Trondheim, Norway. Soil deposits at the 
site consist of fluvial layers of sand, silt and gravel deposited by the meandering Gaula River. These fluvial layers are underlain by young and slightly overconsolidated deltaic and marine sediments (Reite, 1994; Reite et al., 1999). Results from a comprehensive geotechnical and geophysical characterisation campaign for this site are summarised in Quinteros et al. (2019).

\section{Soil tested}

The sand used in this study was sampled from borehole OYSB22 at a depth of $14.5 \mathrm{~m}$. A particle size distribution (PSD) curve obtained following ISO (2016) is shown in Fig. 1. Particle sizes at $10 \%$ and $50 \%$ passing levels are equal to $D_{10}=120 \mu \mathrm{m}$ and $D_{50}=600 \mu \mathrm{m}$, respectively. The coefficients of uniformity and curvature are $C_{\mathrm{u}}=6.7$ and $C_{\mathrm{c}}=1.2$, respectively. Øysand is a well-graded sand (SW) according to ASTM D2487-11. The unit weight of solid particles is $\gamma_{\mathrm{s}}=26.55 \mathrm{kN} / \mathrm{m}^{3}$ following ISO (2015). Maximum and minimum void ratios obtained using the Norwegian Geotechnical Institute (NGI) in-house method (Lunne et al., 2019) are $e_{\max }=0.723$ and $e_{\min }=0.384$, respectively. Detailed inspection of 500 particles shows that about two thirds of the particles are subangular to angular $(25 \%$ angular, $40 \%$ subangular, $23 \%$ subrounded, $11 \%$ rounded and $1 \%$ well rounded). These values were determined by comparing particle shapes seen through a microscope against the classification chart by Pettijohn (1975). Main minerals within the sand fraction are quartz and feldspars, whereas the fines particles (defined here as smaller than $63 \mu \mathrm{m}$ ) are made of illite and chlorite. Based on the inherent characteristics of Øysand soil, a challenging image processing from $\mu \mathrm{CT}$-scanning was expected. In general, large particles can be scanned with more accuracy than smaller particles. As a result, the shape of smaller particles may not be as well defined as the shape of their larger counterparts. In addition, $\mu \mathrm{CT}$ scanning of saturated soil is challenging because water absorbs about two-thirds of the X-rays. Metallic particles are also more difficult to penetrate with X-rays, which may induce image artefacts such as contrast loss in areas with different densities. Given the typical current technical limitations of X-ray $\mu \mathrm{CT}$, ideal soil samples for $\mu \mathrm{CT}$ scanning are poorly graded coarse sands with uniform mineralogy and no fines, such as Hostun HN31 or Reigate sands. These are also plotted in Fig. 1 for comparative purposes.

\section{Field sampling}

Ground freezing of clean sand deposits. Experimental evidence shows that heave expansion of saturated clean sands decreases with increasing vertical effective stress $\left(\sigma_{\mathrm{v}}^{\prime}\right)$ (Yoshimi et al., 1978). Three poorly graded clean sands (Toyoura, Niigata and Tonegawa) subjected to different levels of $\sigma_{\mathrm{v}}^{\prime}$ prior to freezing showed a logarithmic decrease in frost heave expansion with increasing $\sigma_{\mathrm{v}}^{\prime}$ (Fig. 2(a)) in a one-dimensional freezing cell (Yoshimi et al., 1978). Depending on the sand tested, heave-expansion due to freezing was subdued for $\sigma_{\mathrm{v}}^{\prime}$ levels ranging between 7 and $<40 \mathrm{kPa}$. No measurable heave was observed for $\sigma_{\mathrm{v}}^{\prime}$ values larger than $40 \mathrm{kPa}$. This suggests that heave-expansion during ground freezing may take place only at shallow depths.

Øysand frost-heave susceptibility assessment. The sand tested in this study contains about 6-7\% non-plastic silt, depending on the soil classification system used (Fig. 1). Silt increases the frost-heave susceptibility of a soil (Yoshimi et al., 1978). Therefore, a comprehensive laboratory study on the frost-heave susceptibility of Øysand soil was needed. For this analysis, the sand was dry deposited to a conservative value of relative density $\left(D_{\mathrm{r}} \sim 80 \%\right)$ compared to its in situ value $\left(D_{\mathrm{r}} \sim 56 \%\right)$ and tested inside a one-dimensional freezing cell (Fig. 2(b)) under a range of $\sigma_{\mathrm{vc}}^{\prime}$ values. Frost-heave results for the Øysand soil tested (Fig. 2(a)) agreed with the observations of Yoshimi et al. (1978) in that

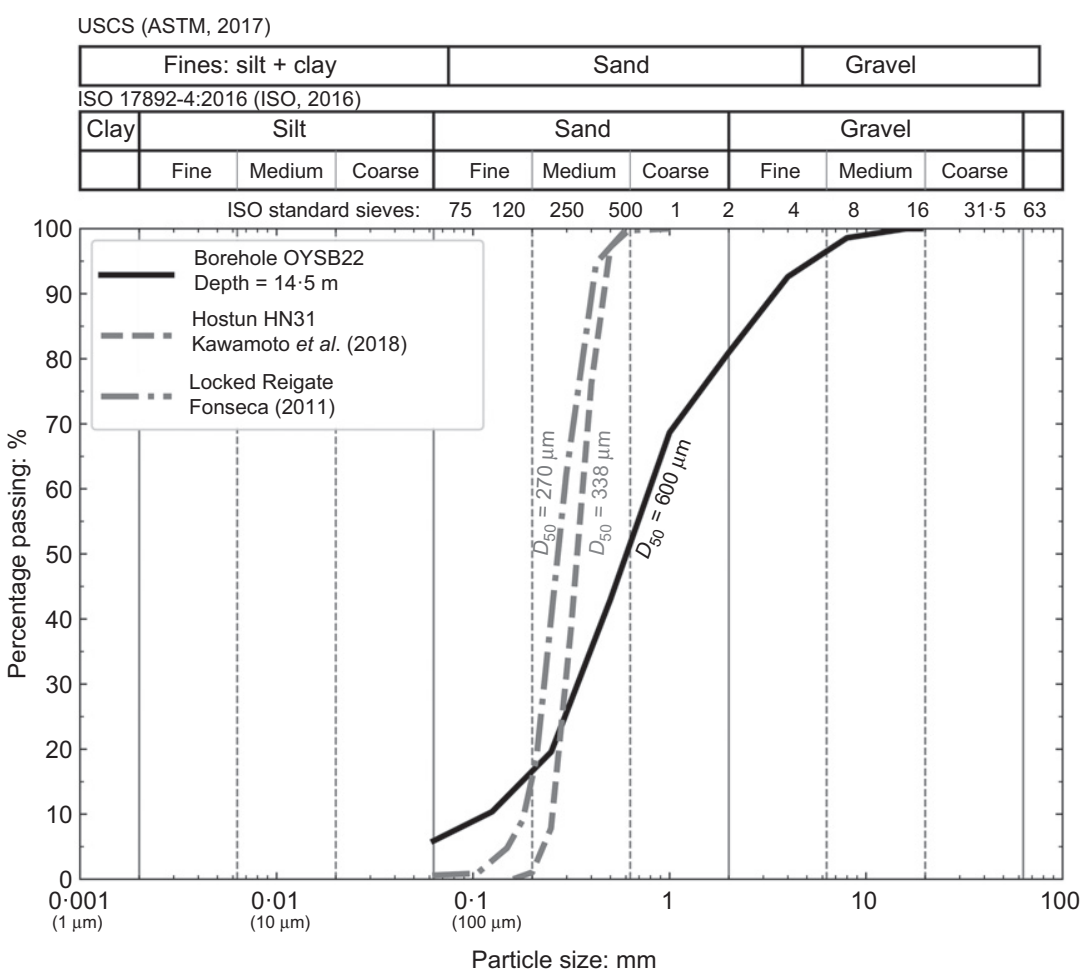

Fig. 1. Particle size distribution of the undisturbed Øysand soil sampled as per ISO (2016) compared to other sands used in $\mu$ CT analyses 


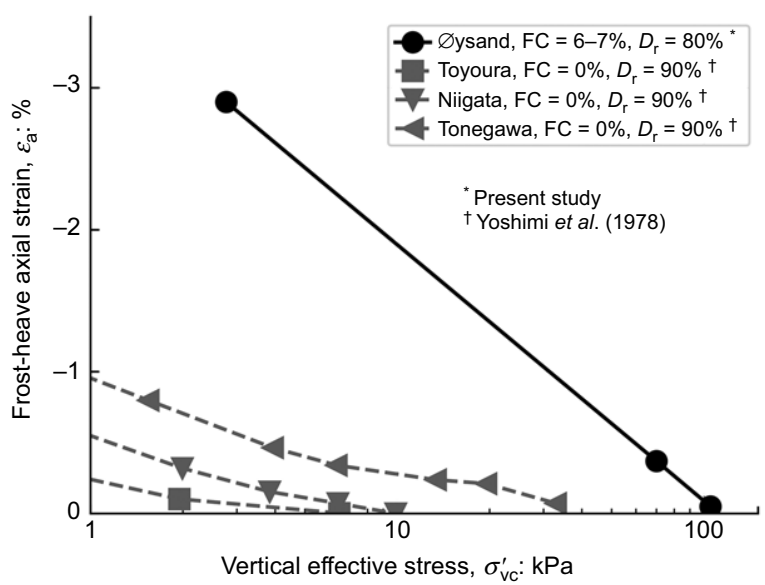

(a)

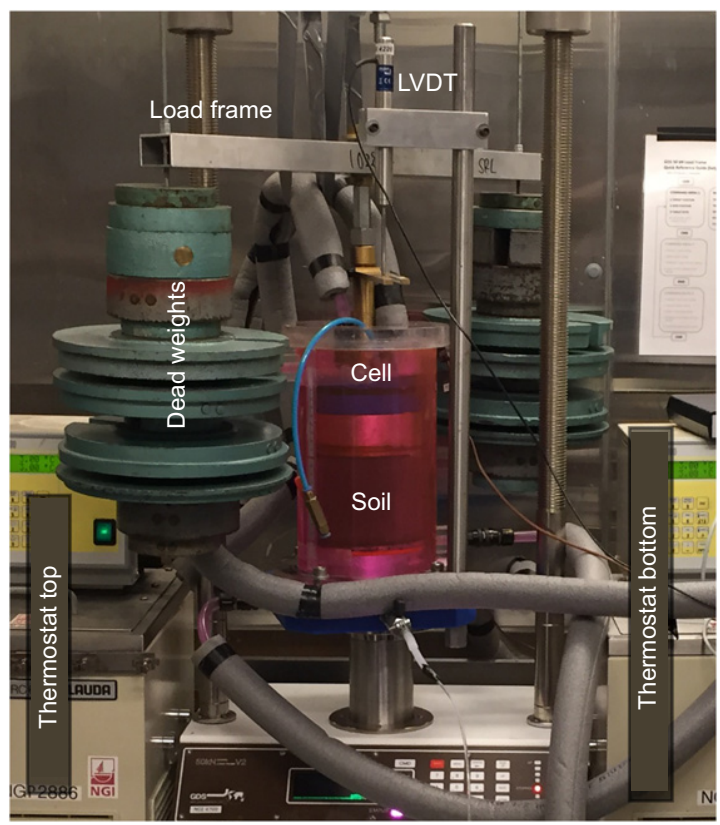

(b)

Fig. 2. Frost-heave susceptibility: (a) frost-heave expansion plotted against increasing vertical effective stress for Øysand and other sands (after Yoshimi et al., 1978); (b) experimental apparatus used in this study

the higher the $\sigma_{\mathrm{v}}^{\prime}$ applied, the smaller the frost-heave expansion observed. The threshold $\sigma_{\mathrm{v}}^{\prime}$ at which the frostheave expansion of the Øysand soil stopped was around $100 \mathrm{kPa}$. This is lower than the in situ $\sigma_{\mathrm{vc}}^{\prime}(\sim 114 \mathrm{kPa})$ of the looser undisturbed Øysand soil samples tested in this study. This finding informed and validated the use of ground freezing to obtain high-quality Øysand samples from the field. Further details on this frost-heave susceptibility analysis are outside the scope of this paper and are described elsewhere.

Ground freezing for undisturbed field sampling of Øysand soil. Ground freezing was achieved by circulating cold brine (calcium chloride $(\mathrm{CaCl})$ ) at $-32^{\circ} \mathrm{C}$ through preinstalled freezing pipes. The brine never came into contact with the in situ soil while soil heat was continuously extracted for 1 month. A thermistor string installed near the freezing pipes recorded the decrease of ground temperature over time. Sampling started once the soil temperature reached $-17^{\circ} \mathrm{C}$. This temperature was deemed cold enough to ensure that the ground was frozen (Yoshimi et al., 1978). Sampling was conducted using a special triple-tube coring system (similar to the Geobor-S system) that allowed flushing of cold air at $-20^{\circ} \mathrm{C}$ through the drill string down to the drill bit to avoid thawing during coring. After sampling, cored undisturbed frozen samples were immediately marked, wrapped in bubble plastic and stored in a freezer at the site. Freezer and samples were then promptly transported to the NGI headquarters in Oslo, Norway. The temperature of frozen samples was continuously monitored using thermometers with data loggers during sampling, field storage, transportation and after laboratory storage. The field installations needed for ground freezing and sampling along with a frozen sample are shown in Fig. 3. Sampling campaign details, including field data information and related costs, are outside the scope of this publication and are discussed elsewhere.

\section{Specimen preparation and reconstitution}

Undisturbed frozen specimens. The void ratio $(e)$ of frozen undisturbed specimens was determined following Vaid \& Sivathayalan (1996) through

$$
e=\left(\frac{M-M_{\mathrm{s}}}{M_{\mathrm{s}}}\right) \frac{\rho_{\mathrm{s}}}{\rho_{\mathrm{i}}}
$$

where $M$ and $M_{\mathrm{s}}$ are the initial wet mass and the solids mass of the specimens, respectively; $\rho_{\mathrm{S}}$ is the solids density and $\rho_{\mathrm{i}}$ is the ice density $\left(0.917 \mathrm{~g} / \mathrm{cm}^{3}\right)$. The $D_{\mathrm{r}}$ of an undisturbed frozen sample retrieved from a depth of $14.5 \mathrm{~m}$ was about $56 \%$. However, note that $D_{\mathrm{r}}$ values vary significantly depending on the methods used for $e_{\min }$ and $e_{\max }$ determination (Lade et al., 1998; Cubrinovski \& Ishihara, 2002; Lunne et al., 2019). The frozen sample diameter $(D)$ was $103 \mathrm{~mm}$. If such samples were $\mu \mathrm{CT}$ scanned in the apparatus available for this study, the image voxel size would be $\sim 80 \mu \mathrm{m}$, yielding a $D_{50} /$ voxel size ratio of $7 \cdot 5$, which means that a $D_{50}$ particle will be represented by only $7 \cdot 5$ voxels, thus not sufficient for a detailed fabric analysis (other studies have achieved $D_{50} /$ voxel size ratios of 20 or even 67 on different sands, see PSDs in Fig. 1). To obtain a smaller voxel size, frozen specimens with $D=25.3 \mathrm{~mm}$ and height $(H)=31 \mathrm{~mm}$ were sub-cored using a diamond drill bit mounted inside a temperature-controlled room at $-9^{\circ} \mathrm{C}$ to avoid thawing. As particle motion during $\mu \mathrm{CT}$ scanning is detrimental to image quality and can alter the initial soil fabric, the scan duration was limited to $25 \mathrm{~min}$ to avoid thawing. In addition, the specimen was surrounded by two polyethylene isolation layers and passive cooling elements (hard plastic ice-filled packs), as shown in Fig. 4. The recorded temperature variations for different configurations used to prevent thawing are shown in Fig. 4(f). The final set-up with two isolation layers, cooling elements and a starting temperature of $-15^{\circ} \mathrm{C}$ effectively delayed thawing for $32 \mathrm{~min}$ and was adopted as part of the scanning protocol.

Reconstituted specimens. The DD reconstitution method used involved funnelling dry sand into a mould at constant fall height (Ishihara, 1996). The MT technique involved placing soil with a water content of $4 \%$ and adopted an undercompaction factor $\left(U_{1}\right)$ of $5 \%$, which is suitable for the target $D_{\mathrm{r}}$ (Ladd, 1978). The MT specimen was tamped in two layers using a tamper with diameter equal to 0.98 of the internal mould diameter. The first (bottom) layer had a lower mass (based on $U_{1}$ ) than the second (upper) layer. The WS method used involved spooning dry soil into a mould partially filled with water (e.g. Wanatowski \& Chu, 2008). For the SD method, dry soil was initially placed into the 


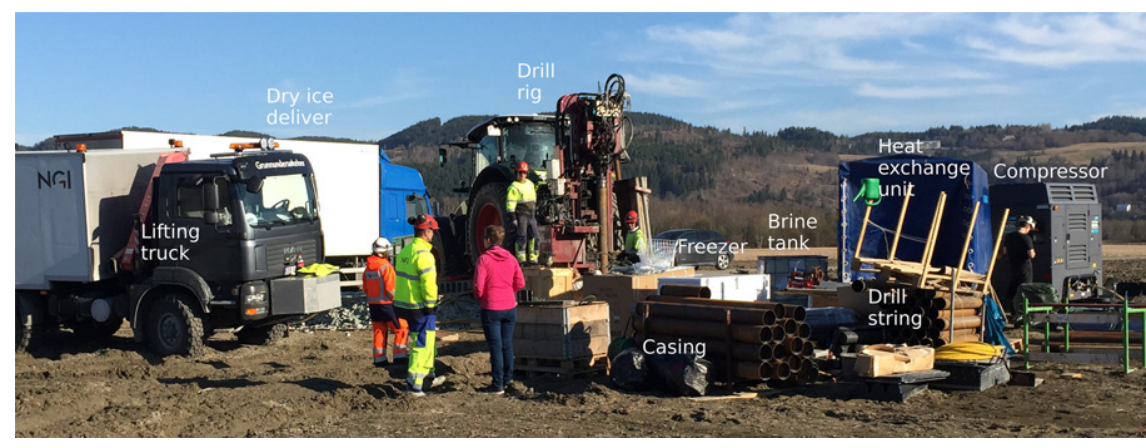

(a)

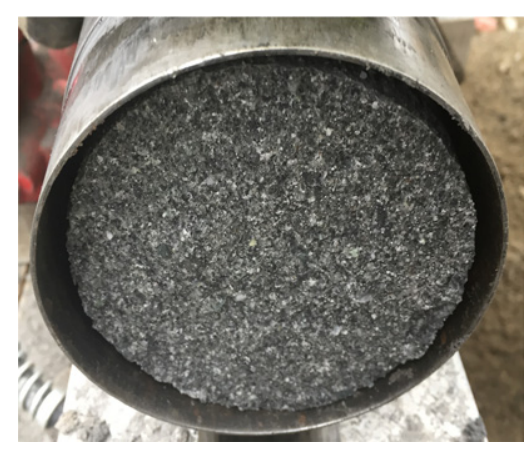

(b)

Fig. 3. Ground freezing technique used for field sampling: (a) overview of the installations needed at the site; (b) frozen Øysand sample obtained with this method

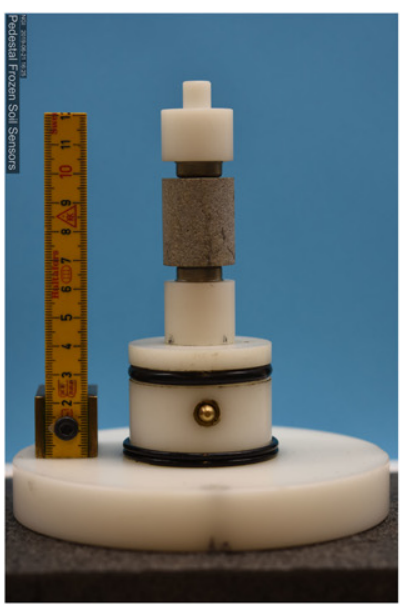

(a)

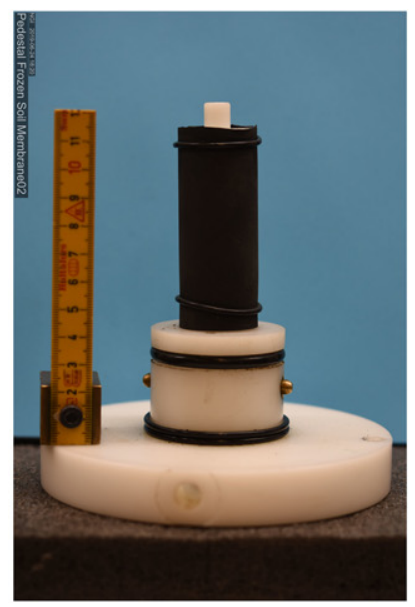

(b)



(c)

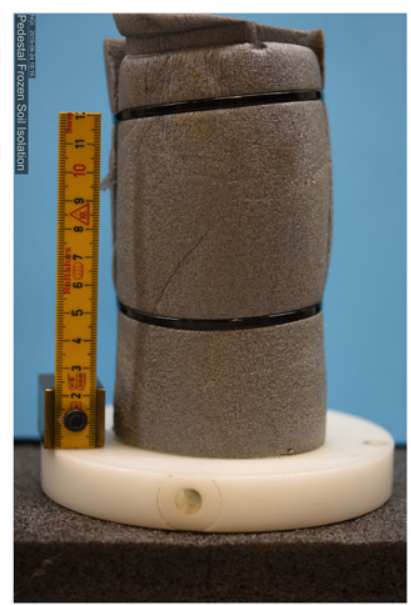

(d)

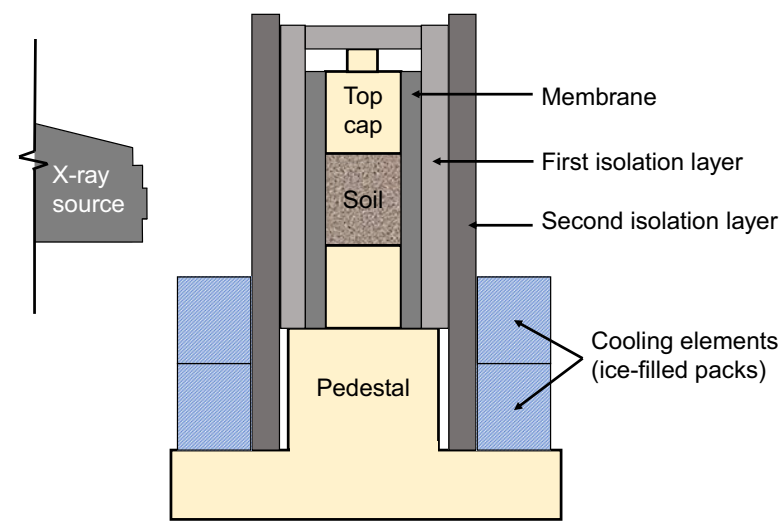

(e)

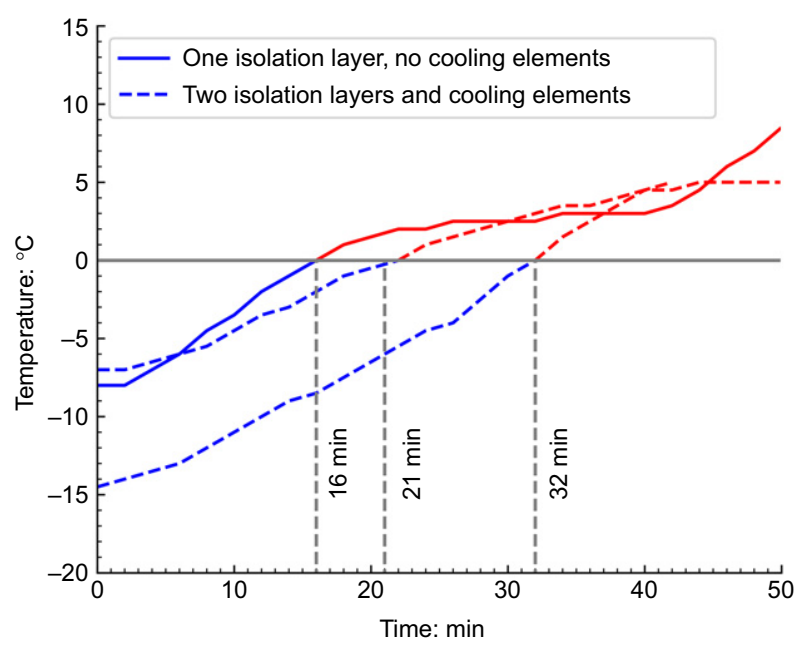

(f)

Fig. 4. Experimental set-up used to delay thawing: (a) soil specimen with temperature sensors on top and bottom; (b) membrane installation; (c) first isolation layer; (d) second isolation layer (final configuration; cooling elements not shown); (e) schematic diagram; (f) variation of temperature plotted against time for various configurations

mould, which was already coupled with an extended collar and prefilled with de-aired water. Then, the slurry was thoroughly mixed, de-aired and the collar was removed (Carraro \& Prezzi, 2008). The collar length used in this SD technique was equal to the mould height, and the soil dry mass $\left(m_{\mathrm{d}}\right)$ ratio after deposition was $m_{\mathrm{d} \text {,collar }} / m_{\mathrm{d} \text {, mould }}=0 \cdot 1$. Schematic representations of the reconstitution methods used are shown in Fig. 5. The mould used was made of highly
X-ray-transparent carbon fibre and had an internal diameter of $22.3 \mathrm{~mm}$. The target height of the specimens was $35 \mathrm{~mm}$, leading to an $H / D$ ratio of $\sim 1 \cdot 6$. Although this was slightly higher than the $H / D$ ratio of the frozen specimens, it allowed for a better voxel size $(23 \mu \mathrm{m})$ than that obtained in the frozen specimen $(26 \mu \mathrm{m})$. For comparison, the maximum particle size recommended by ASTM D4767 for triaxial specimens shall be smaller than $1 / 6$ of the specimen diameter. 


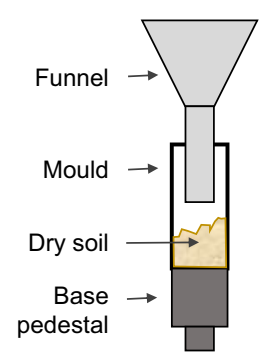

(a)

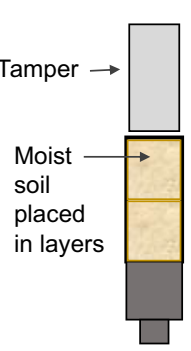

(b)

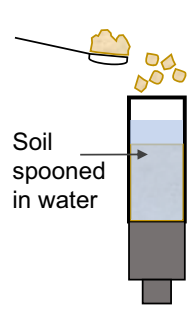

(c)



(d)

Fig. 5. Schematic representation of the reconstitution methods used: (a) dry deposition (DD); (b) moist tamping (MT); (c) water sedimentation (WS) by spooning; and (d) slurry deposition (SD)

In the case of the Øysand soil tested, particles $>3.7 \mathrm{~mm}$ (corresponding to less than about $7 \%$ of the sample mass) would have been sieved out in the case of triaxial tests. In the present image analysis study, such a recommendation was not followed. Instead, boundary effects issues were accounted for by digitally excluding all particles in direct contact with the mould during the image analyses. The dry mass of the reconstituted specimens was $24 \cdot 22 \mathrm{~g}$. The potential error to achieve a given $D_{\mathrm{r}}$ increases significantly when dealing with such small amounts of soil (Vaid \& Sivathayalan, 1996). To achieve comparable values of $D_{\mathrm{r}}$ for the reconstituted specimens, a high-precision micrometre frame was used to control the initial specimen height. Gentle tapping on the base pedestal was used for densification to the target $D_{\mathrm{r}}$ for DD, WP and SD specimens. Several trials were needed to achieve $D_{\mathrm{r}}$ values as close as possible to the $D_{\mathrm{r}}$ of the frozen soil; see Table 2 for a summary of the final $D_{\mathrm{r}}$ values.

Micro-computed tomography and image analysis procedures Micro-computed tomography. X-ray methods have been used for over 60 years to study soils. For instance, Roscoe et al. (1963) used two-dimensional (2D) X-ray radiography scans to observe strain fields in sand. Over recent decades, technological advances in X-ray scanning have allowed image voxel size to decrease from millimetres to a few micrometres. X-ray $\mu \mathrm{CT}$ scanning has helped to obtain invaluable information about soil structure such as interparticle contacts, grain morphology, shear bands, particle breakage and cementation (Viggiani \& Tengattini, 2019). Details about $\mu \mathrm{CT}$ of geomaterials are found in Desrues $\mathrm{et} \mathrm{al}$. (2006). The $\mu \mathrm{CT}$ scanner used in this research is a Nikon Metrology XT H-225LC device, located at NGI in Oslo, Norway. The scanner has a high-power cone-beam source, a high-resolution detector panel and a precision rotating table. In this study, $\mu \mathrm{CT}$ scans were performed using a voltage of $80 \mathrm{kV}$ and a current of $60 \mathrm{~mA}$. During scanning, total specimen rotation was $360^{\circ}$, while the exposure time per projection was $1 \mathrm{~s}$. The magnification, voxel size, number of projections and frame average of all scans are summarised in

Table 2. Relative density, micro-computed tomography scanning parameters and anisotropy of specimens tested

\begin{tabular}{l|l|l|l|l|l}
\hline Parameter/specimen & Frozen & DD & MT & WS & SD \\
\hline Relative density: \% & 56 & 57 & 56 & 56 & 56 \\
Magnification & $7 \cdot 7$ & $8 \cdot 7$ & $8 \cdot 7$ & $8 \cdot 7$ & $8 \cdot 7$ \\
Voxel size: $\mu \mathrm{m}$ & 26 & 23 & 23 & 23 & 23 \\
$\begin{array}{l}\text { Number of } \\
\text { projections }\end{array}$ & 1500 & 2319 & 2319 & 1500 & 2319 \\
Frame average & 32 & 64 & 64 & 32 & 64 \\
Scalar anisotropy & $0 \cdot 64$ & $0 \cdot 77$ & $0 \cdot 49$ & $0 \cdot 98$ & $0 \cdot 59$ \\
\hline
\end{tabular}

Table 2. Thousands of radiograms obtained during a single $\mu \mathrm{CT}$ scan were reconstructed using the filtered back projection technique to a three-dimensional (3D) volume using the software VG-Studio Max (Volume Graphics, 2014). The minimum voxel size of the scanner is $3 \mu \mathrm{m}$ (spot size). This means that most silt particles could theoretically be observed at maximum magnification. However, given the Øysand soil's non-trivial PSD and mineralogy, as discussed earlier, and the dimensions of the scanned specimens, the voxel size achieved allowed a representation of a $D_{10}$ particle with $\sim 5$ voxels along its equivalent diameter, whereas a $D_{50}$ particle could be represented by $\sim 23$ voxels. The voxel size needed for a fabric analysis depends on the soil characteristics, the particles of interest and the purpose of the study. Previous studies have achieved greater or similar voxel sizes but for different purposes and using different soils such as poorly graded uniform sands with simpler mineralogy. For example, $D_{50}$ values of Reigate and HN31 sands were represented by $\sim 55$ voxels (Fonseca et al., 2013) and 23 voxels (Andò et al., 2012), respectively, the latter being similar to the voxel size achieved in the present study. Conversely to previous studies, Øysand particles have different grey values that reflect their complex mineralogy, and three out of the five samples tested were not dry (frozen, WS and SD), as shown in Fig. 6 for typical cross-sections along the $3 \mathrm{D} \mu \mathrm{CT}$ volumes. All $\mu \mathrm{CT}$ images were postprocessed and analysed to obtain quantitative descriptors of the initial fabric of the sand, as described next.

Image analysis to obtain fabric descriptors. Image analysis of $\mu \mathrm{CT}$-scans was performed to obtain soil fabric information in terms of particle orientation and directional anisotropy. Void ratio and PSD variations along the specimen height were also determined from the $3 \mathrm{D} \mu \mathrm{CT}$ volumes to assess specimen uniformity, which is a fundamental requirement of rigorous element testing protocols (Kuerbis \& Vaid, 1988; Frost \& Park, 2003; Carraro \& Prezzi, 2008). Soil fabric from $\mu C T$ images can be quantified using tensors of $(a)$ particles' orientation, $(b)$ voids' orientation, or (c) contacts between particles (Oda, 1972; Kanatani, 1984; Oda et al., 1985). A thorough study on the metrology of contacts determination from $\mu \mathrm{CT}$ images by Wiebicke et al. (2017) showed that contacts are systematically over-detected using standard thresholding and automatic segmentation methods, leading to the rise of non-existent contacts (i.e. particles that are close to each other but that do not touch can be artificially detected as 'in contact'). Given the complex PSD and mineralogy of the Øysand soil tested, the presence of water in some specimens, and the voxel size obtained using the specimen size and scanner available, this study focused on the assessment of the initial fabric in terms of particle orientations, not contacts. The scalar anisotropy 

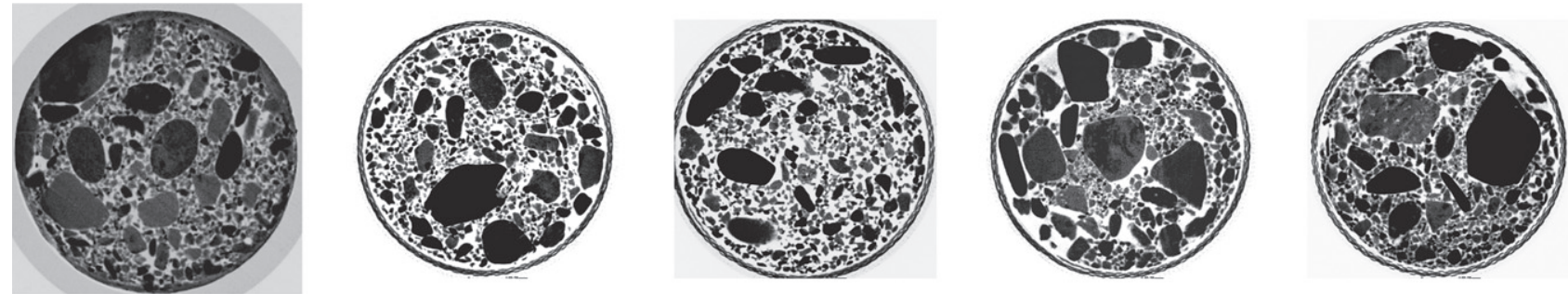

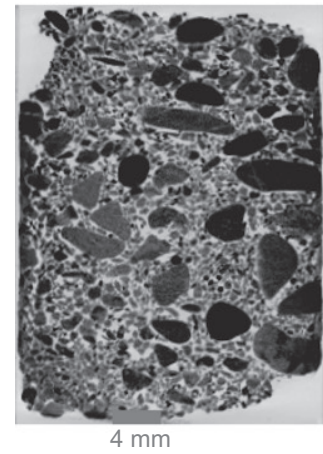

(a)

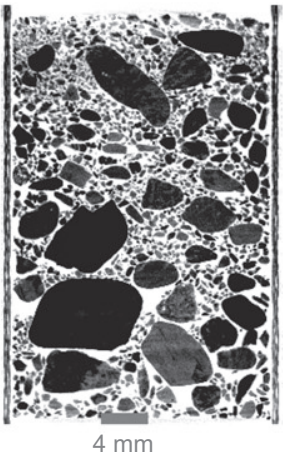

(b)

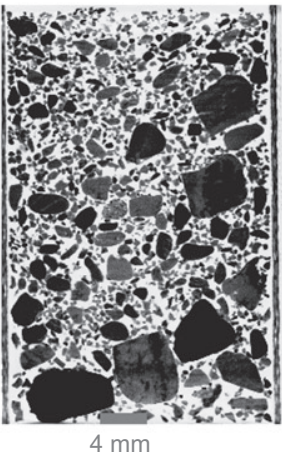

(c)

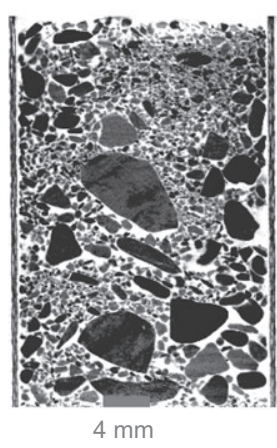

(d)

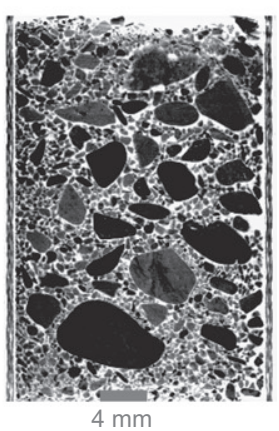

(e)

Fig. 6. Typical horizontal (top) and vertical (bottom) cross-sections from the 3D volumes obtained using $\mu$ CT: (a) frozen; (b) dry deposition (DD); (c) moist tamping (MT); (d) water sedimentation (WS) by spooning; and (e) slurry deposition (SD) specimens

factor was calculated for this purpose, as explained below, in detail. The image-processing steps included preparation, filtering, enhancing, binarisation, segmentation and labelling of particles for data analysis. Beam hardening corrections were applied on the specimens containing ice and water. Beam hardening artefacts arise when scanning saturated soil. The main issue experienced was that the grey scales of the fines content and water were similar. In spite of this, however, the sand grains still showed more contrast than water. Details about image-processing steps for granular materials can be found elsewhere (e.g. Fonseca, 2011; Andò, 2013). The open-source Python-based software Spam (the software for the practical analysis of materials) developed by Andò et al. (2017) and Stamati et al. (2020) at 3SR Laboratory in Grenoble, France was used for this task. Other algorithms used were based on the scikit-image package developed by van der Walt et al. (2014), the ndimage package from scipy (scipy.org), and the porespy package (Gostick et al., 2019), which were implemented in scripts using version 3.6 of the open-source software Python (Van Rossum \& Drake, 2009). Image preparation required masking images to a certain region of interest. For example, the orientation of particles close to the boundary may not be entirely representative of a reconstitution method due to the interaction between the mould and particles nearby. The same is applicable to cut boundary particles of the frozen specimen. Hence, particles touching boundaries were disregarded from the analyses (see Fig. 7(b)). The $\mu \mathrm{CT}$ images were filtered using 3D median and Gaussian filters. Then, morphological opening and closing filters were used on the grey images to enhance particle shapes prior to binarisation. Binarisation was done either using the automatic image thresholding algorithm developed by Otsu (1979) or manually, depending on the binary results achieved. Small erosion

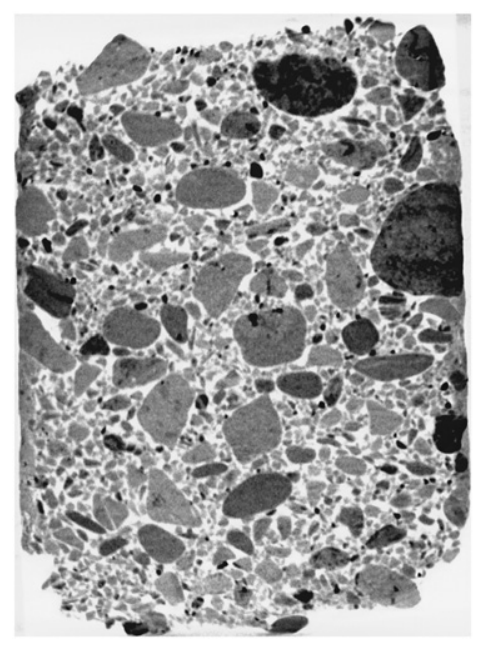

(a)

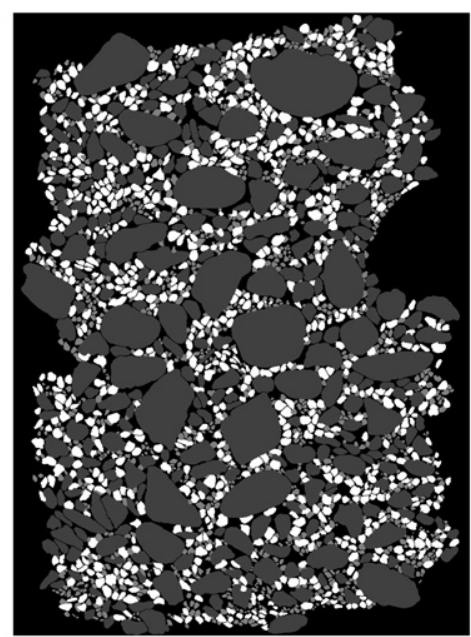

(b)

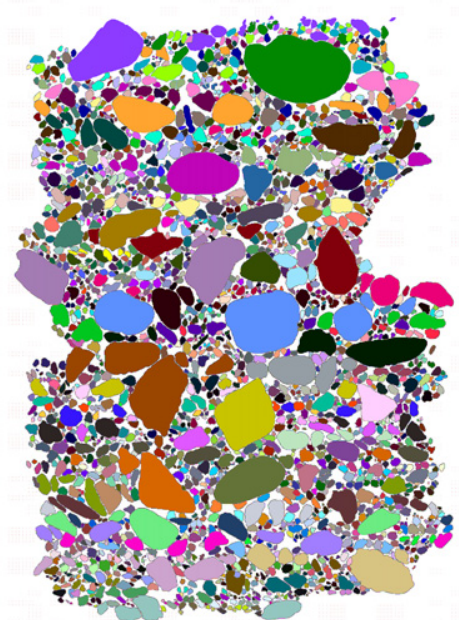

(c)

Fig. 7. Typical segmentation/labelling/analysis process steps used: (a) filtered and enhanced image; (b) binary image; (c) individually labelled particles 
and large opening binary algorithms were used to correct for errors related to the shape of the binarised particles when needed. Details about filtering, enhancing and thresholding for binarisation are described in Gonzalez \& Woods (1992). Particle segmentation was carried out automatically using the ITK-watershed algorithm implemented in Spam; labelling and post-processing was also done using Spam. Synthetic images, created by drawing well-defined 3D objects using the ITK-snap software (Yushkevich et al., 2006), were used to validate all scripts. An example of the binarisation and segmentation steps is illustrated in Fig. 7.

The statistical description of initial fabric orientations was then assessed on the segmented and labelled particles using the second-order tensor after Kanatani (1984)

$$
\boldsymbol{N}=\frac{1}{C} \sum_{\alpha=1}^{C} \boldsymbol{o}^{\alpha} \otimes \boldsymbol{o}^{\alpha}
$$

where $C$ is the total number of vectors in the system and $\boldsymbol{o}$ is an individual orientation vector in the representative volume; the $\otimes$ operation is the dynamic product of the two vectors and the $\boldsymbol{o}^{\alpha}$ are the projections or components of the $\alpha$ th unit vector $\boldsymbol{o}$ with respect to the $x_{i}$ Cartesian coordinate. The deviatoric part of the fabric tensor $D$ is calculated using

$$
D=\frac{15}{2}\left(\boldsymbol{N}-\frac{1}{3} \boldsymbol{\delta}\right)
$$

where $\boldsymbol{\delta}$ is the identity tensor. Specimen anisotropy can be quantified by the anisotropy factor $a$, which is a scalar value calculated from $D$ as proposed by Gu et al. (2017)

$$
a=\sqrt{\frac{3}{2} D: D}
$$

The higher the value of $a$, the higher the anisotropy of a specimen is. This approach was also presented and used by Wiebicke et al. (2019) to measure fabric evolution in shear bands.

\section{ANALYSIS OF RESULTS \\ Particle orientation analysis}

$3 D$ particle orientations. The 3D particles' longest axes orientations of the labelled particles, which are obtained from the moment of inertia (or second moment of area) eigenvectors of the particles using Spam, can be presented as binned Lambert azimuthal equal area (Fig. 8). A vector in space representing the particle major axis orientation
(Fig. 8(a)) can be illustrated as a point in the Lambert projection (Fig. 8(b)) (Wiebicke et al., 2019). In this context, $\theta$ describes the particle major axis alignment with respect to the vertical direction, whereas $\beta$ defines the projection of the particle major axis orientation on the horizontal plane. For example, the vector shown in Fig. 8(a) lies in space with $\beta=315^{\circ}$ and polar angle $\theta$ of about $44^{\circ}$ (Fig. 8(b)). A point at the centre of the circle of the Lambert azimuthal plot would represent a particle whose major axis is oriented along the $z$-direction (i.e. complete verticality of its major axis). Conversely, a point lying on the edge of the plot $\left(\theta=90^{\circ}\right)$ would represent a particle whose major axis is completely horizontal. Binned projections help to represent all vectors (particles) falling within a certain range (or bin), as shown in Fig. 8(c). The 3D particle orientation analysis of all specimens is shown in Fig. 9. These 3D polar plots provide a general overview of particle major axis orientations. For the frozen specimen (Fig. 9(a)), the predominant horizontal orientations of the major axis particles are clustered at the edge of the polar plot with $\beta$ values equal to about $90^{\circ}$ and $270^{\circ}$ and with $\theta$ angles between $75^{\circ}$ and $90^{\circ}$. Particles' major axis orientations become more dispersed with decreasing $\theta$, meaning that there are fewer particles oriented vertically. The preferred concentrations of particle orientation with respect to $\beta$ may be the result of the fluvial sand's deltaic depositional history as the Gaula River meanders in the Øysand valley in Trondheim, Norway. Thus, it may be argued that particles might be deposited mainly horizontally and with a particular horizontal bias on the horizontal plane controlled by the past river flow direction (e.g. Bertin \& Friedrich, 2016). However, the $3 \mathrm{D}$ particle orientations plots for the reconstituted specimens suggest that none of the reconstitution methods replicates this $\beta$ horizontal orientation bias observed for the undisturbed fluvial sand specimen. This is understandable given that all reconstitution methods used simply impart vertical particle deposition through air/water or moist placement. Nevertheless, for all reconstitution methods, particles are mostly aligned with the horizontal directions. An exception to this general trend is the apparent small bias observed for the WS method whose particles tend to concentrate horizontally around $180^{\circ}<\beta<270^{\circ}$. This may be an artefact of the spooning process given that, while the mould was kept in its original place, the spoon was not systematically rotated around the vertical axis of the mould during each spooning step. Particles deposited using the MT and SD methods (Figs $9(\mathrm{c})$ and $9(\mathrm{e})$ ) show a more random tendency than their DD (Fig. 9(b)) and WS (Fig. 9(d)) counterparts to align along the horizontal direction $\left(60^{\circ}<\theta<90^{\circ}\right)$ with no preferred $\beta$ horizontal orientation.

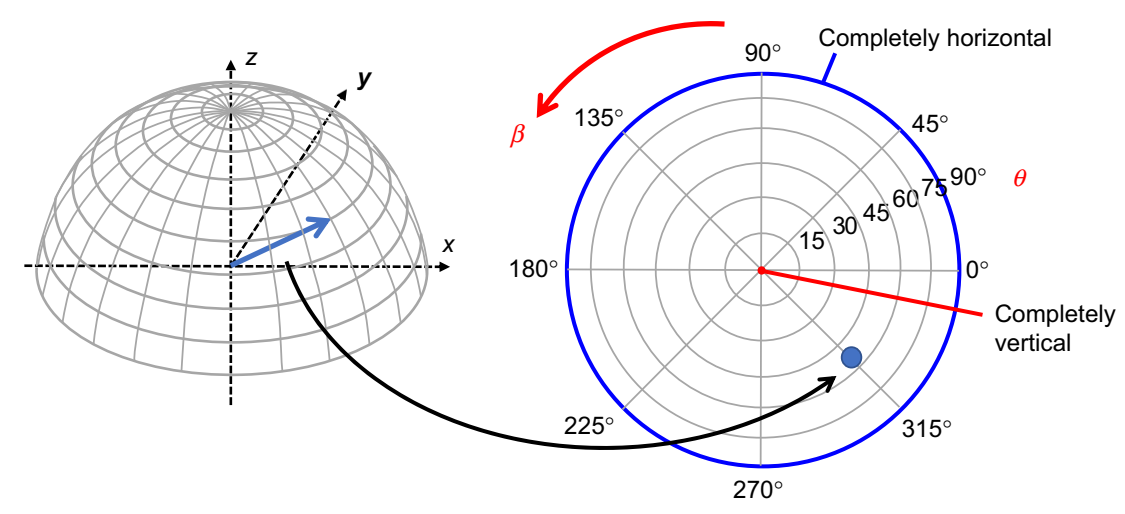

(a)

(b)

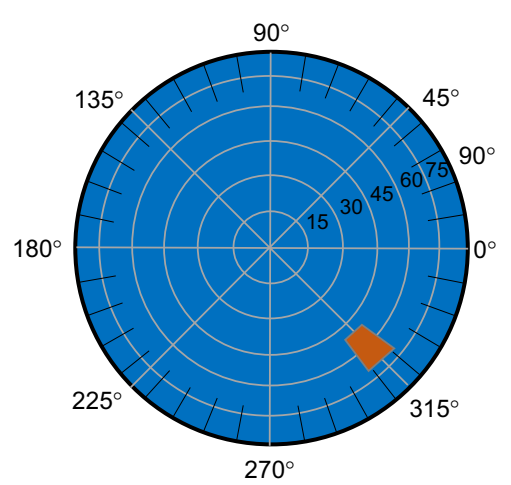

(c)

Fig. 8. Visualisation of the plotting of individual particle major axis orientations and binned projection used to simplify plotting of many orientations (taken from Wiebicke et al. (2019)): (a) vectorial presentation; (b) Lambert azimuthal projection; (c) binned projection 




(a)

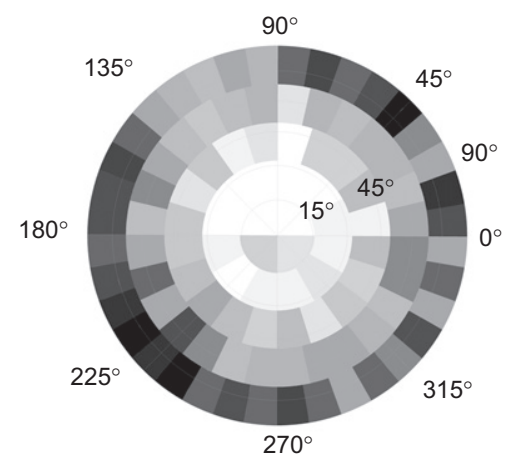

(b)



(c)

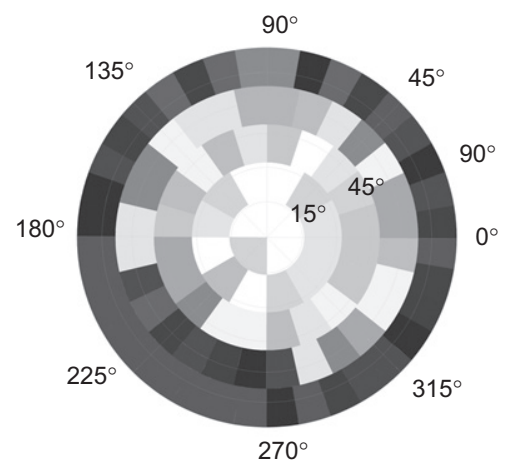

(d)

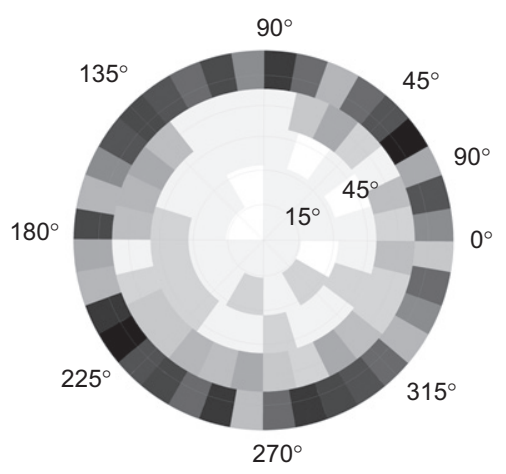

(e)

Fig. 9. Polar plots of 3D particle major axis orientations for all specimens tested: (a) frozen; (b) dry deposition (DD); (c) moist tamping (MT); (d) water sedimentation (WS); (e) slurry deposition (SD) (note: coloured vertical scale represents the number of particles per bin)

Particle orientations and anisotropy of different particle size ranges of the frozen soil. An additional analysis of the long axis orientations of particles of different sizes was conducted for the frozen specimen to assess whether distinct ranges of particle sizes may display preferred orientations. The particle orientation and anisotropy factor was calculated for particles of the frozen soil for three different particle size ranges: $D_{100^{-}}$ $D_{50}, D_{50}-D_{30}$ and $D_{30}-D_{10}$ (Fig. 10). Note that due to the voxel size achieved in this study, the long axis particle orientations can be calculated more accurately for larger particles than for smaller ones. Therefore, the particle size range below $D_{10}$ was not plotted in this analysis to limit the influence of the smallest particles in the sample tested. The orientations of most of the $D_{100}-D_{50}$ particles (354 in total) are clustered at the edge of the polar plot with $\beta$ values equal to about $150^{\circ}$ and $270^{\circ}$ and with $\theta$ angles between $75^{\circ}$ and $90^{\circ}$ (Fig. 10(a)), in general accordance with Fig. 9(a). $D_{50^{-}}$ $D_{30}$ particles (293 in total) also show a stronger tendency to align along the horizontal direction (Fig. 10(b)), mainly between $\beta=90^{\circ}$ to $135^{\circ}$ and $\theta=60^{\circ}$ to $90^{\circ}$. Conversely, particles between $D_{30}$ and $D_{10}$ (412 in total) show a much less pronounced alignment towards the horizontal (Fig. 10(c)), with no clear preferred concentration. The anisotropy factors of these three particle size ranges are $a_{D_{100}-D_{50}}=1 \cdot 22, a_{D_{50}-D_{30}}$ $=0.98$ and $a_{D_{30}-D_{10}}=0.67$. This analysis shows that, within the frozen undisturbed soil specimen, larger particles are much more oriented along the horizontal direction than smaller particles. Therefore, the fabric information obtained from the particle major axis orientations of predominantly larger particles may be a useful proxy of the initial fabric of the whole Øysand sample tested (Fig. 9(a)). But while the particle major axis orientation is useful to systematically compare this feature of the fabric of reconstituted specimens against those obtained for the frozen soil, the anisotropy factor $a$, void ratio variations and particle segregation over height must also be evaluated before any conclusions are made regarding the suitability of any reconstitution method to replicate the initial state of the frozen Øysand soil.

\section{Fabric anisotropy and uniformity}

Anisotropy factor of particle orientation. The anisotropy factor $a$ obtained for the entire 3D volume defining each sample tested is summarised in Table 2 and Fig. 11. These findings suggest that the anisotropy of the particles of the undisturbed fluvial sand is best reproduced in the laboratory using the SD reconstitution method. Among all methods used, the MT and WS methods are the least capable of properly replicating the initial fabric anisotropy of the undisturbed fluvial sand. These data on the undisturbed fabric of fluvial sand obtained through high-quality ground freezing sampling and $\mu \mathrm{CT}$ scanning are very rare. However, but perhaps more importantly, they finally help to explain why the mechanical response of slurry-deposited (or waterpluviated) sand specimens reconstituted in the laboratory has been repeatedly shown to best match the mechanical response of truly undisturbed sand specimens, as reported in past systematic studies (e.g. Vaid et al., 1999).

Specimen uniformity in terms of void ratio variations. According to Andò (2013) the void ratio of sands can be estimated from $\mu \mathrm{CT}$ images by three different techniques, namely: $(a)$ 'continuum' measurements using binary images; (b) grain-based void ratio using triangulations (Delaunay or Set Voronoi); or $(c)$ by measuring the volume of the specimen from binary images by dilation, filling holes and erosion algorithms. The technique chosen in this study is the first one using (Fonseca, 2011)

$$
e_{\mathrm{CT}}=\frac{N_{\mathrm{t}}-N_{\mathrm{s}}}{N_{\mathrm{s}}}
$$




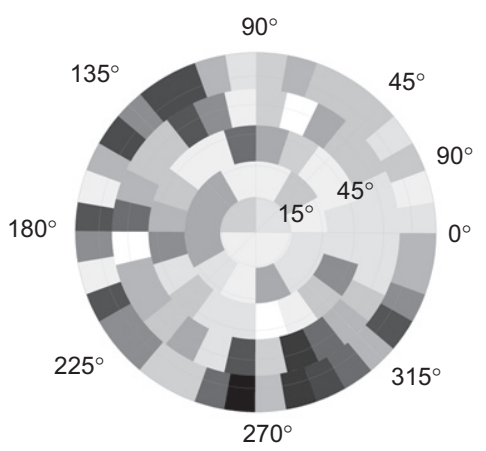

(a)

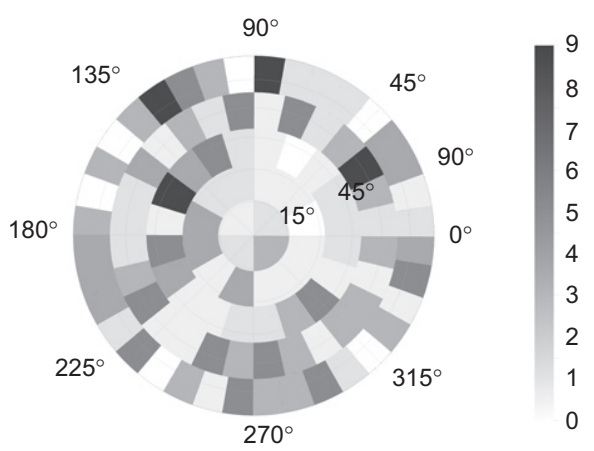

(b)

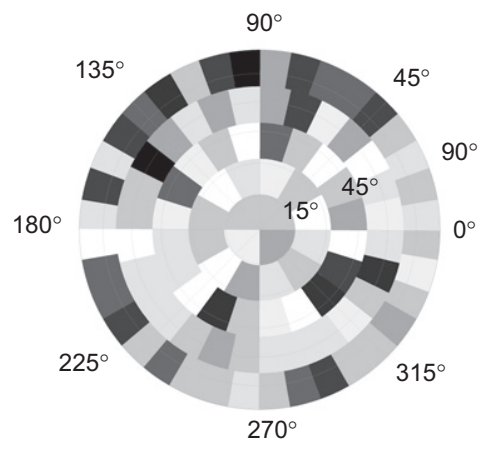

(c)

Fig. 10. Polar plots of 3D particle major axis orientations of frozen sample, for particle size ranges between: (a) $D_{100}$ and $D_{50}$, anisotropy $a=1 \cdot 22$; (b) $D_{50}$ and $D_{30}$, anisotropy $a=0.98$; (c) $D_{30}$ and $D_{10}$, anisotropy $a=0.67$ (same scale for all polar plots)

where $e_{\mathrm{CT}}$ is the void ratio measured using $\mu \mathrm{CT} ; N_{\mathrm{t}}$ is the total number of voxels; and $N_{\mathrm{s}}$ is the number of voxels of the solid particles on a $3 \mathrm{D}$ volume. The void ratio of each specimen was calculated using equation (5) for binary cross-sections (on volumes of 35 voxels) along the specimen height to obtain continuous 3D profiles. The borders of binary images were slightly masked by a few voxels to avoid introducing empty space around the images in the calculations. Results are plotted in Fig. 12, with $e_{\mathrm{CT}}$ values plotted against the elevation of each cross-section $\left(H_{i}\right)$ normalised by the specimen height. The $e_{\mathrm{CT}}$ values of the frozen specimen (Fig. 12(a)) vary across the specimen height from about 0.49 to 0.56 averaging around its global $e$ (see Table 3 ). For the DD specimen, extreme $e_{\mathrm{CT}}$ values ranged between 0.44 and 0.60 and $e_{\mathrm{CT}}$ varied more over the specimen height (see Fig. 12(b) and coefficient of variation in Table 3). DD creates a much less uniform fabric and void ratio profile than those observed for the frozen specimen. The MT specimen displays

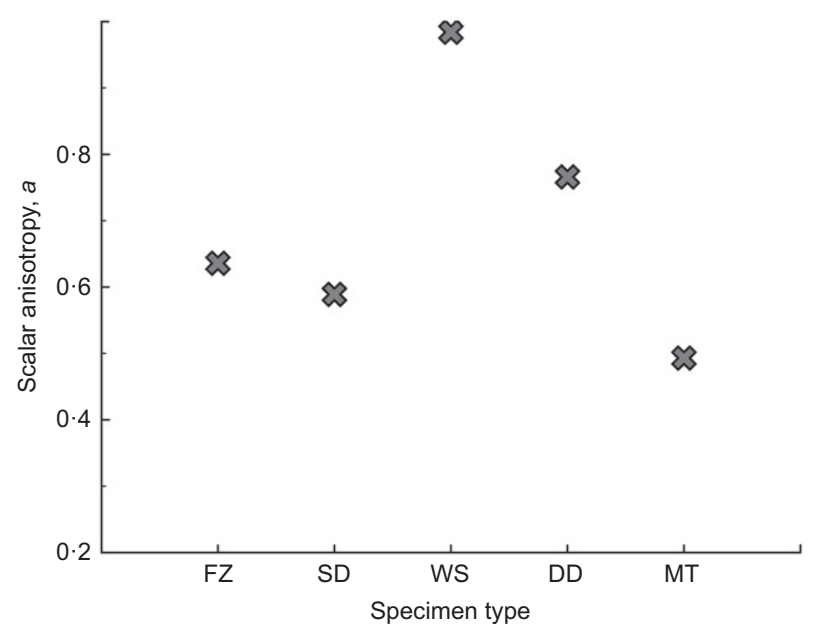

Fig. 11. Fabric anisotropy: average values of scalar anisotropy for the frozen (FZ), and reconstituted (DD, MT, WS and SD) specimens

the largest $e_{\mathrm{CT}}$ variation among all specimens tested (Fig. 12(c) and Table 3) with extreme values between $0 \cdot 40$ and $0 \cdot 61$. Even though under-compaction was employed during reconstitution, the MT specimen still showed a clear distinctive interface between the upper and lower layer. The bottom half of the specimen is in general looser than the upper half. The large variation of the void ratio, within the MT specimen, is in agreement with previous studies of poorly graded sands (see Frost \& Park, 2003; Shi et al., 2019; Vaid \& Negussey, 1988). This issue of large variation is rarely checked or addressed in industry practice. The $e_{\mathrm{CT}}$ of the WS specimen (Fig. 12(d)) varies in a very distinctive manner over the specimen height (limit values between 0.44 and 0.59): the specimen is denser in the bottom and looser in the top. Finally, $e_{\mathrm{CT}}$ variations for the SD specimen are the smallest among all of the specimens tested (see Fig. 12(e) and Table 3) with limit values between $0 \cdot 45$ and $0 \cdot 60$. The SD average $e_{\mathrm{CT}}$ value is also the closest to the average value of the frozen specimen, although a larger variation across the height is observed than that noted for the undisturbed specimen. This finding is consistent with other rigorous, systematic studies on SD reconstitution (Kuerbis \& Vaid, 1988; Carraro \& Prezzi, 2008; Dominguez-Quintans et al., 2019). SD tends to create more homogeneous specimens across the height than other reconstitution methods, particularly for well-graded sands such as the Øysand sample tested in the present study. The summary of void ratio statistics (Table 3 ) confirms that SD and MT methods produce the most and least uniform Øysand sand specimens, respectively, among all specimens tested in this study.

Specimen uniformity in terms of particle size variations. Uniformity analyses accounting for PSD variations along the specimen height were obtained from the segmented and labelled 3D $\mu \mathrm{CT}$ scans. Particle sizes were calculated using the label-based measurements implemented in Spam by fitting each labelled particle with an ellipse and obtaining the length of the largest principal axis from the moment of inertia tensor. Note that any measurement of particle size based on segmentation procedures (i.e. quantifying the largest or smallest principal axis, or fitting an ellipse to a labelled volume) is only an approximation of the actual particle size. Moreover, the quality of the segmentation procedure used will influence the resulting sizes of the particles analysed (i.e. over- or under-segmentation may create larger or smaller fictive particles). To overcome 


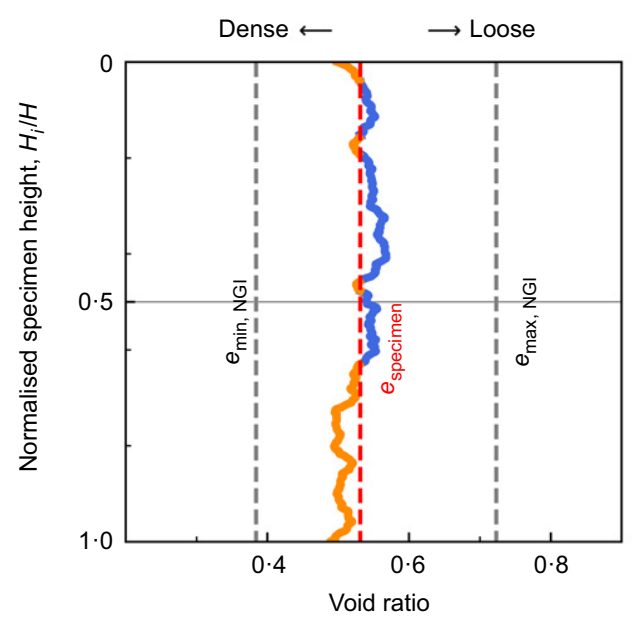

(a)

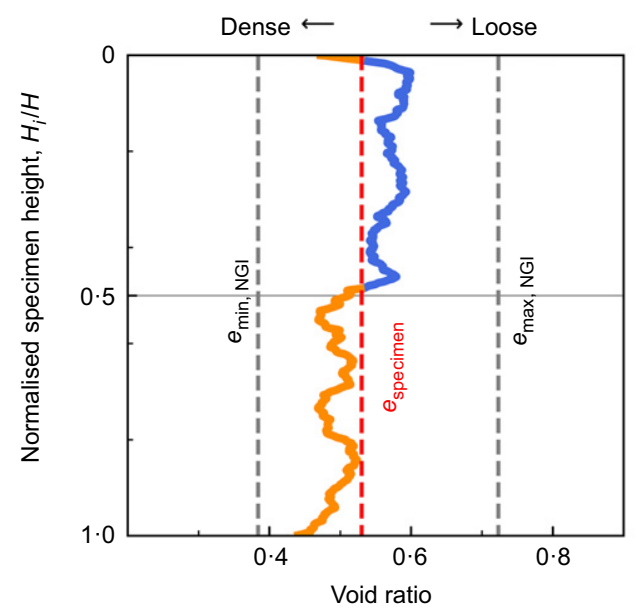

(d)

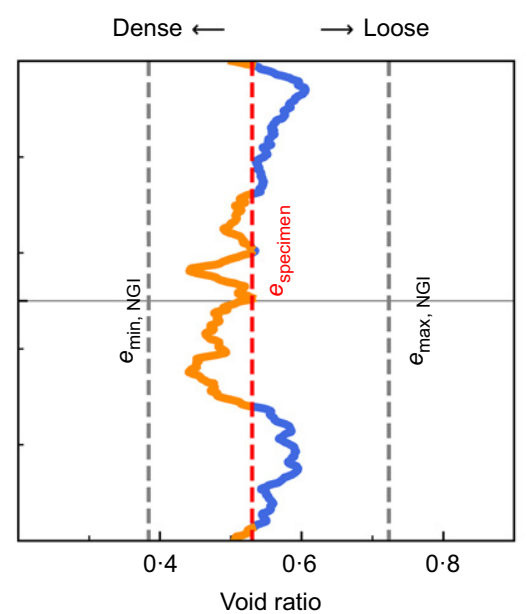

(b)

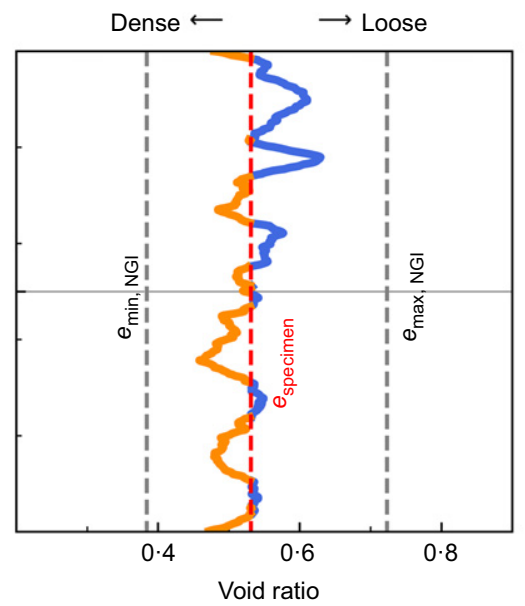

(e)

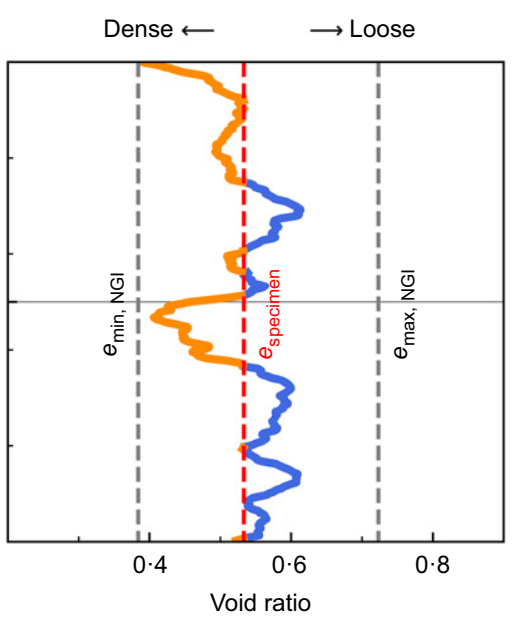

(c)

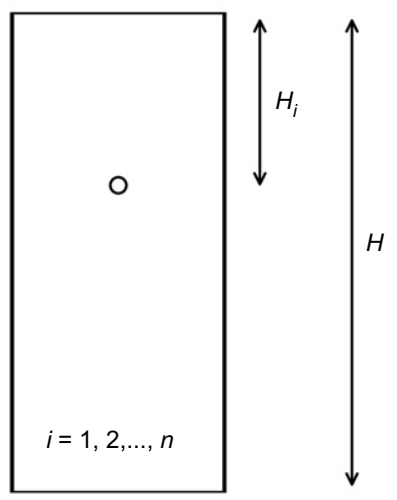

(f)

Fig. 12. Variation of void ratio along the normalised specimen height for: (a) frozen (FZ); (b) DD; (c) MT; (d) WS; and (e) SD specimens

Table 3. Void ratio of undisturbed and reconstituted specimens (shown in Fig. 12)

\begin{tabular}{l|c|c|c}
\hline \multirow{2}{*}{ Specimen } & \multirow{2}{*}{ Global $e$} & \multicolumn{2}{|c}{ Local $e_{\mathrm{CT}}$} \\
\cline { 3 - 4 } & & Average & Coefficient of variation: \% \\
\hline Frozen & 0.53 & 0.53 & 4 \\
DD & 0.53 & 0.54 & 8 \\
MT & 0.53 & 0.54 & 9 \\
WS & 0.53 & 0.52 & 8 \\
SD & 0.53 & 0.53 & 6 \\
\hline
\end{tabular}

over-segmentation issues, a voxel-based threshold to the contacts was applied, as in the approach developed by Wiebicke (2020). To investigate particle segregation across the specimen height, labelled volumes were divided into three regions (top, centre and bottom) across the height. Splitting specimen volumes into three distinct regions is a process that will invariably introduce errors because boundary particles along regional interfaces may be split, which can affect PSD calculations; therefore, boundary particles were removed from these analyses. The PSDs of the three regions of the frozen specimen, which are compared to the PSDs of all reconstituted specimens tested in Fig. 13, show a very small yet inherent segregation of the undisturbed specimen - that is, coarser particles tend to concentrate slightly more within the top and centre of the specimen, whereas slightly finer particles locate in the bottom. In general, the DD specimen (Fig. 13(a)) shows a similar type of segregation across the specimen height, with slightly coarser particles mostly located within the top and centre layers. In contrast, the MT and WS specimens (Figs 13(b) and 13(c)) are the least uniform and show the largest amount of segregation among all of the reconstituted specimens tested. Segregation imparted by MT and WS was also higher than that observed for the natural, undisturbed fluvial sand. The segregation observed for the WS specimen may possibly be the result of the inconsistent spooning process, as discussed earlier in the section entitled '3D particle orientations'. The SD method (Fig. 13(d)) shows the least amount of segregation across the specimen height among all reconstitution methods used. SD also replicates the inherent segregation of the natural fluvial sand (i.e. slight increase in fines in the specimen bottom). As has been well established by other rigorous systematic studies (Kuerbis \& Vaid, 1988; Carraro \& Prezzi, 2008; Dominguez-Quintans et al., 2019), SD produces extremely uniform and homogeneous specimens of sands deposited under water or in a slurry environment (note that water pluviation can only be used for very uniform clean sands). The present study confirms this previous finding as SD yields the highest quality specimens of fluvial Øysand soil, compared to all of the other reconstitution methods tried. Table 4 summarises and compares the various factors described in this study and highlights the capabilities of 




(a)

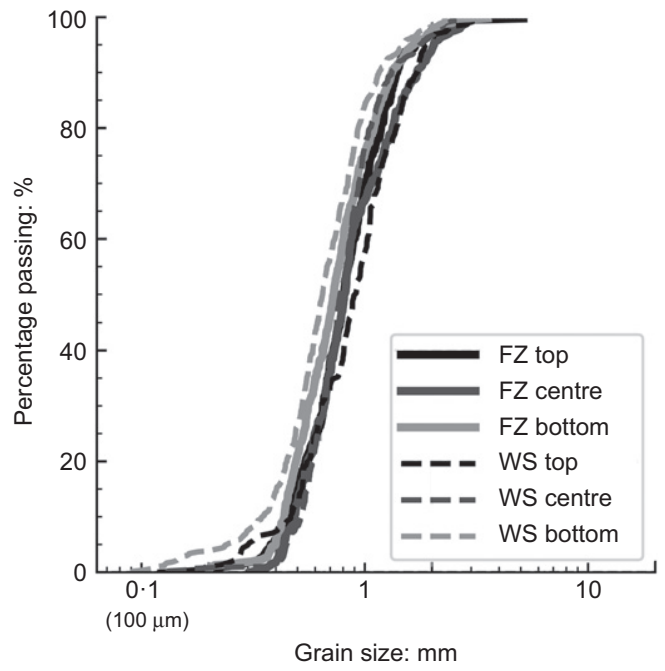

(c)

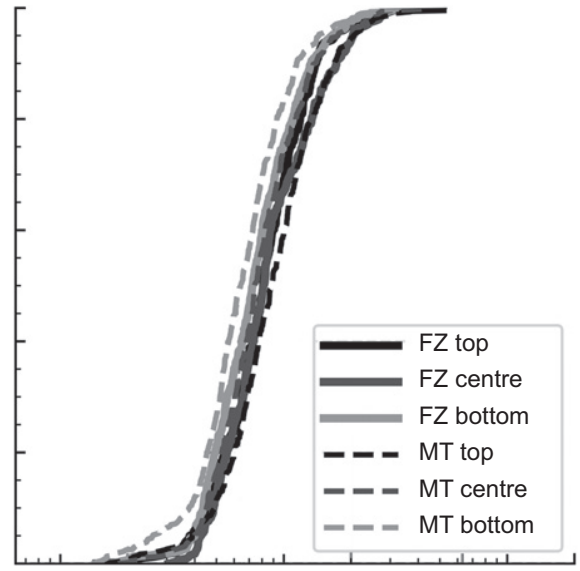

(b)

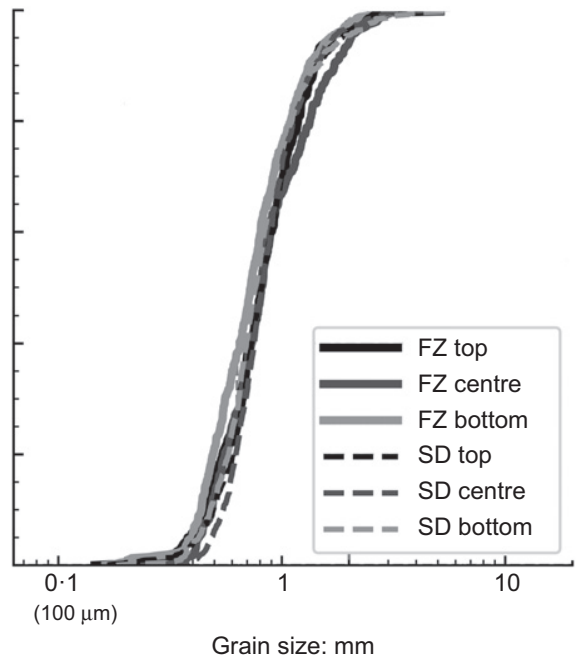

(d)

Fig. 13. Variation of particle size distributions obtained from image processing along specimen height for the frozen (FZ) as well as (a) DD, (b) MT, (c) WS and (d) SD specimens

Table 4. Summary of the 3D fabric analyses conducted for all specimens tested

\begin{tabular}{l|c|c|c|c}
\hline Specimen & Particle orientation & Anisotropy & Void ratio uniformity & PSD uniformity \\
\hline DD & X & $\checkmark$ & X & $\checkmark$ \\
MT & X & X & X & X \\
WS & X & $\checkmark$ & $\checkmark$ & X \\
SD & $\checkmark$ & $\checkmark$ \\
\hline
\end{tabular}

$\checkmark$ : acceptable; X: not acceptable.

each reconstitution method used in an attempt to replicate the initial sate of the undisturbed frozen Øysand soil sample.

\section{CONCLUSIONS}

This research clarifies a long pending issue in soil mechanics and geotechnical engineering: which method should be used to reconstitute fluvial sand specimens in the laboratory? The initial fabric of undisturbed fluvial sand is characterised using high-quality samples obtained by ground freezing and $\mu \mathrm{CT}$ analysis. The initial fabric of undisturbed fluvial Øysand soil and its counterparts reconstituted by dry deposition, water sedimentation, moist tamping and slurry deposition was systematically evaluated in terms of particle orientation and its anisotropy. Uniformity analyses were also carried out in terms of void ratio variations and particle segregation within the specimens. The following conclusions are derived from the study.

(a) For the undisturbed Øysand specimen, longer/larger particles are mostly oriented along the horizontal direction and their anisotropy (assessed by the anisotropy factor $a$ ) is particle size dependent. The undisturbed Øysand sand has a distinctive 3D particle orientation that was not replicated by any of the laboratory reconstitution methods used. This preferred concentration of orientations may be the result of past fluvial depositional/flow processes at the site. This aspect deserves further investigation in future studies. 
(b) All reconstitution methods used impart particle orientation mostly along the horizontal direction.

(c) The anisotropy factor $a$ of the undisturbed fluvial sand tested was best replicated by the slurry deposition method. All other reconstituted methods are unable to replicate the initial anisotropy of the undisturbed fluvial Øysand soil.

(d) Local void ratio variations along the height of the undisturbed and slurry deposition specimens of Øysand are relatively small. Excessive, unacceptable local void ratio variations were observed for the other reconstitution methods used, with the largest variations imparted by moist tamping.

(e) Some inherent particle segregation is observed in the undisturbed fluvial sand, which was replicated, to some extent, by the slurry deposition method. Dry deposition induced more particle segregation, but the greatest amount of segregation was imparted by water sedimentation and moist tamping.

Slurry deposition seems to be the most suitable reconstitution method to replicate the inherent particle orientation and its anisotropy, void ratio distribution and uniformity of the Øysand fluvial sand. This finally explains why past systematic research studies have consistently demonstrated that slurry deposition is the most suitable laboratory reconstitution method to reproduce the macro stress-strain response of sand deposits formed under water such as fluvial sands (Kuerbis \& Vaid, 1988; Vaid et al., 1999). These findings have a major impact for testing and analyses of the mechanical behaviour and liquefaction of fluvial, offshore and tailings sands.

\section{ACKNOWLEDGEMENTS}

The support of the Norwegian Geotechnical Institute and the Norwegian Research Council is acknowledged with gratitude. The authors' gratitude is extended to Geofrost for their expertise during the ground freezing sampling programme. Special thanks are owed to Cino Viggiani and Edward Andò (3RS Laboratory, Grenoble, France), Joana Fonseca (City University, London, UK) and Heidi Debreczeny Wilkinson, Magnus Soldal, Morten Sjursen and Yusuke Suzuki (NGI, Oslo, Norway) for their support and enlightening discussions during the research.

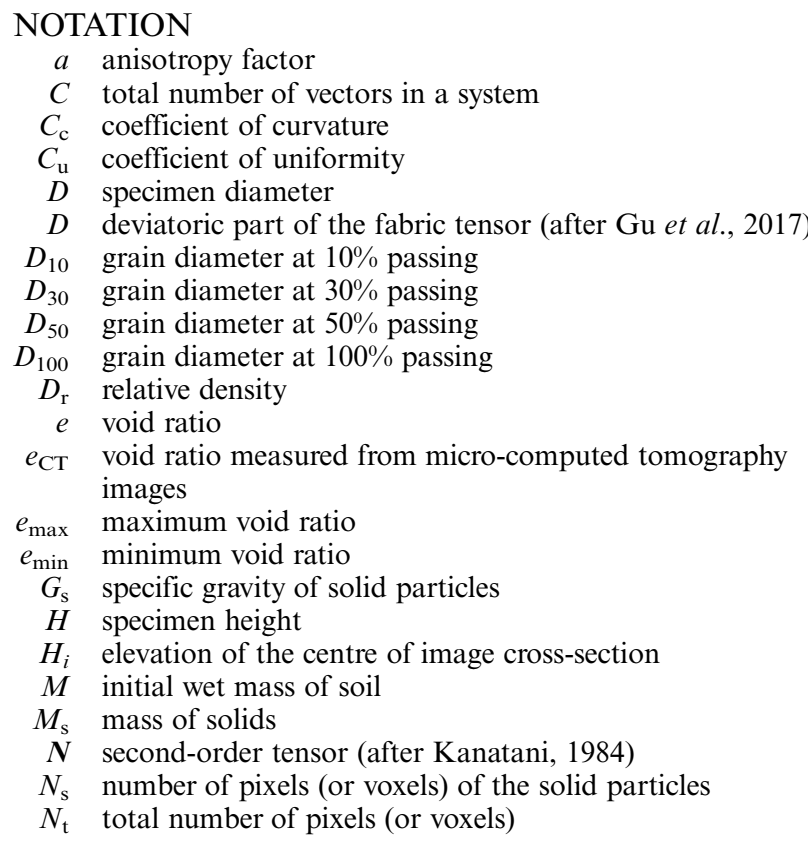

$U_{1} \quad$ undercompaction factor (after Ladd, 1978)

$\beta$ particle major axis orientation on the horizontal plane

$\gamma_{\mathrm{s}}$ unit weight of solid particles

$\theta$ polar angle in Lambert azimuthal projection

$\boldsymbol{o}$ individual orientation vector in the representative volume

$\rho_{\mathrm{i}}$ density of ice

$\sigma_{\mathrm{vc}}^{\prime} \quad$ vertical effective stress at consolidation

\section{REFERENCES}

Andersland, O. B. \& Ladanyi, B. (1994). An introduction to frozen ground engineering, 2nd edn. New York, NY, USA: Chapman \& Hall.

Andò, E. (2013). Experimental investigation of microstructural changes in deforming granular media using X-ray tomography. University of Grenoble, Grenoble, France.

Andò, E., Hall, S. A., Viggiani, G., Desrues, J. \& Besuelle, P. (2012). Grain-scale experimental investigation of localised deformation in sand: a discrete particle tracking approach. Acta Geotech. 7, No. 1, 1-13.

Andò, E., Cailletaud, R., Roubin, E. \& Stamati, O. (2017). Spam: the software for the practical analysis of materials. J. Open Source Softw. 5, No. 51, 2286.

Arthur, J. R. F. \& Phillips, A. B. (1975). Homogeneous and layered sand in triaxial compression. Géotechnique 25, No. 4, 799-815, https://doi.org/10.1680/geot.1975.25.4.799.

ASTM (2017). D2487-17: Standard practice for classification of soils for engineering purposes (Unified Soil Classification System). ASTM International, West Conshohocken, PA, USA.

Bertin, S. \& Friedrich, H. (2016). Field application of close-range digital photogrammetry (CRDP) for grain-scale fluvial morphology studies. Earth Surf. Processes Landforms 41, 1358-1369.

Bishop, A. W. (1948). A new sampling tool for use in cohesionless sands below ground water level. Géotechnique 1, No. 2, 125-301, https://doi.org/10.1680/geot.1948.1.2.125.

Carraro, J. A. H. \& Prezzi, M. (2008). A new slurry-based method of preparation of specimens of sand containing fines. Geotech. Test. J. 31, No. 1, 1-11.

Cubrinovski, M. \& Ishihara, K. (2002). Maximum and minimum void ratio characteristics of sands. Soils Found. 42, No. 6, 65-78.

Desrues, J., Viggiani, G. \& Bésuelle, P. (2006). Advances in X-ray tomography for geomaterials. London, UK: Wiley, ISTE.

Dominguez-Quintans, C., Quinteros, S., Carraro, J. A. H., Zdravkovic, L. \& Jardine, R. J. (2019). Quality assessment of a new in-mould slurry deposition method for triaxial specimen reconstitution of clean and silty sands. In 7 th international symposium on deformation characteristics of geomaterials (IS Glasgow 2019) (eds A. Tarantino and E. Ibraim), https:// doi.org/10.1051/e3sconf/20199202010. Les Ulis, France: E3S Web of Conferences.

Evans, T. M. (2005). Microscale physical and numerical investigations of shear banding in granular soils. PhD dissertation, Georgia Institute of Technology, Atlanta, GA, USA.

Fonseca, J. (2011). The evolution of morphology and fabric of a sand during shearing. $\mathrm{PhD}$ thesis, Imperial College London, University of London, London, UK.

Fonseca, J., O'Sullivan, C., Coop, M. R. \& Lee, P. D. (2013). Quantifying the evolution of soil fabric during shearing using directional parameters. Géotechnique 63, No. 6, 487-499, https://doi.org/10.1680/geot.12.P.003.

Frost, J. D. (1989). Studies on the monotonic and cyclic behavior of sands. PhD thesis, Purdue University, West Lafayette, IN, USA.

Frost, J. D. \& Park, J. Y. (2003). A critical assessment of the moist tamping technique. Geotech. Test. J. 26, No. 1, 57-70.

Ghionna, V. N., Pedroni, S. \& Porcino, D. (2001). Undisturbed sampling by ground freezing at Gioia Tauro site for seismic liquefaction analyses. In XVth ICSMGE: earthquake geotechnical engineering satellite conference 'lessons learned from recent strong earthquakes', pp. 249-254. Lisse, the Netherlands: Balkema.

Gonzalez, R. \& Woods, R. (1992). Digital image processing. Upper Saddle River, NJ, USA: Prentice Hall.

Gostick, J., Khan, Z. A., Tranter, T. G., Kok, M. D. R., Agnaou, M., Sadeghi, M. A. \& Jervis, R. (2019). PoreSpy: a Python toolkit for quantitative analysis of porous media images. 
J. Open Source Softw. 4, No. 37, 1296, https://doi.org/ 10.21105/joss.01296.

Gu, X., Hu, J. \& Huang, M. (2017). Anisotropy of elasticity and fabric of granular soils. Granular Matter 19, No. 2, article 33.

Huang, A. \& Huang, Y. T. (2007). Undisturbed sampling and laboratory shearing tests on a sand with various fines contents. Soils Found. 47, No. 4, 771-781.

Ishihara, K. (1996). Soil behaviour in earthquake geotechnics. Oxford, UK: Clarendon Press.

ISO (International Organization of Standardization) (2015). 17892-3: Geotechnical investigation and testing - laboratory testing of soil - part 3: determination of particle density. Geneva, Switzerland: ISO.

ISO (2016). 17892-4: Geotechnical investigation and testing laboratory testing of soil - part 4: determination of particle size distribution. Geneva, Switzerland: ISO.

Kanatani, K. I. (1984). Distribution of directional data and fabric tensors. Int. J. Engng Sci. 2, No. 22, 149-164.

Kawamoto, R., Andò, E., Viggiani, G. \& Andrade, J. E. (2018). All you need is shape: predicting shear banding in sand with LS-DEM. J. Mech. Phys. Solids 111, 375-392.

Konrad, J. M., St-Laurent, S., Gilbert, F. \& Leroueil, S. (1995). Sand sampling below the water table using the $200 \mathrm{~mm}$ diameter Laval sampler. Can. Geotech. J. 32, No. 6, 1079-1089.

Kuerbis, R. \& Vaid, Y. P. (1988). Sand sample preparation - the slurry deposition method. Soils Found. 28, No. 4, 107-118.

Kuo, C. Y. \& Frost, J. D. (1996). Uniformity evaluation of cohesionless specimens using digital image analysis. J. Geotech. Engng 122, No. 5, 390-396.

La Rochelle, P., Sarrailh, J., Tavenas, F., Roy, M. \& Leroueil, S. (1981). Causes of sampling disturbance and design of a new sampler for sensitive soils. Can. Geotech. J. 18, No. 1, 52-66.

Ladd, R. (1974). Specimen preparation and liquefaction of sands. J. Geotech. Geoenviron. Engng 100, No. 10, 1180-1184, https://doi.org/10.1061/AJGEB6.0000117.

Ladd, C. C., Foot, R., Ishihara, K., Schlosser, F. \& Poulos, H. G. (1977). Stress-deformation and strength characteristics, state of the art report. In Proceedings of the 9th ISFMFE, vol. 4, pp. 421-494. Tokyo, Japan: Japanese Society of Soil Mechanics and Foundation Engineering.

Ladd, R. S. S. (1978). Preparing test specimens using undercompaction. Geotech. Test. J. 1, No. 1, 16-23.

Lade, P. V., Liggio, C. D. \& Yamamuro, J. A. (1998). Effects of non-plastic fines on minimum and maximum void ratios of sand. Geotech. Test. J. 21, No. 4, 336-347.

Lunne, T., Knudsen, S., Blaker, Ø., Vestgarden, T., Powell, J., Wallace, C. \& Ghanekar, R. (2019). Methods used to determine maximum and minimum dry unit weight of sand. Is there a need for a new standard? Can. Geotech. J. 56, No. 4 , 536-553.

Madhusudhan, B. N. \& Baudet, B. A. (2014). Influence of reconstitution method on the behaviour of completely decomposed granite. Géotechnique 64, No. 7, 540-550, https://doi.org/ 10.1680/geot.13.P.159.

Mitchell, J. \& Soga, K. (2005). Fundamentals of soil behavior. New York, NY, USA: John Wiley \& Sons, Inc.

Miura, S. \& Toki, S. (1982). A sample preparation method and its effect on static and cyclic deformation-strength properties of sand. Soils Found. 22, No. 1, 61-77.

Mori, K. \& Sakai, K. (2016). The GP sampler: a new innovation in core sampling. J. Australian Geomech. Soc. 51, No. 4, $131-166$

Mulilis, J. P., Arulanandan, K., Mitchell, J. K., Chan, C. K. \& Seed, H. B. (1977). Effects of sample preparation on sand liquefaction. J. Geotech. Engng Div. 103, No. 2, 91-108.

Oda, M. (1972). The mechanism of fabric changes during compressional deformation of sand. Soils Found. 12, No. 2, $1-18$.

Oda, M., Nemat-Nasser, S. \& Konishi, J. (1985). Stress-induced anisotropy in granular masses. Soils Found. 25, No. 3, 85-97.

Otsu, N. (1979). A threshold selection method from gray level histograms. IEEE Trans. Syst., Man Cybern. 9, No. 1, 62-66.

Pettijohn, F. J. (1975). Sedimentary rocks, 3rd edn. New York, NY, USA: Harper and Row Publishers.

Quinteros, S., Gundersen, A., L'Heureux, J. S., Carraro, J. A. H. \& Jardine, R. J. (2019). Øysand research site: geotechnical characterisation of deltaic sandy-silty soils. AIMS Geosci. 5, No. 4, 750-783.

Reite, A. J. (1994). Weischelian and Holocene geology of Sør-Trøndelag and adjacent parts of Nord-Trøndelag County, Central Norway. $N G U$ Bull. 426, 1-30.

Reite, A. J., Sveian, H. \& Erichsen, E. (1999). Trondheim fra istid til nåtid - landskapshistorie og løsmasser, Gråsteinen no. 5. Trondheim, Norway: NGU (Geological Survey of Norway) (in Norwegian).

Robertson, P. K., Wride, C. E., List, B. R., Atukorala, U., Biggar, K. W., Byrne, P. M. \& Zavodni, Z. (2000). The CANLEX project: summary and conclusions. Can. Geotech. J. 37, No. 3, 563-591.

Roscoe, K. H., Arthur, J. R. F. \& James, R. G. (1963). The determination of strains in soils by an X-ray method. Civ. Engng Public Works Rev. 58, 873-876 and 1009-1012.

Schneider, H. R., Chameau, J. L. \& Leonards, G. A. (1989). Chemical impregnation of cohesionless soils. Geotech. Test. J. 12, No. 3, 204-210.

Sego, D. C., Robertson, P. K., Sasitharan, S., Kllpatrick, B. L. \& Pillai, V. S. (1994). Ground freezing and sampling of foundation soils at Duncan Dam. Can. Geotech. J. 31, No. 6, 939-950.

Shi, J., Haegeman, W., Mascini, A. \& Cnudde, V. (2019). X-ray analysis on the effect of sample preparation on the microstructure of calcareous sands. Mar. Georesour. Geotechnol. 39, No. 2, $1-10$.

Shi, J., Haegeman, W. \& Cnudde, V. (2020). Anisotropic small-strain stiffness of calcareous sand affected by sample preparation, particle characteristic and gradation. Géotechnique 71, No. 4 , 305-319, https://doi.org/10.1680/jgeot.18.P.348.

Silver, M. L., Tatsuoka, F., Phukunhaphan, A. \& Avramidis, A. S. (1980). Cyclic undrained strength of sand by triaxial test and simple shear test. Proceedings of the 7th world conference on earthquake engineering, Istanbul, Turkey, vol. 3, pp. $281-288$.

Stamati, O., Andò, E., Roubin, E., Cailletaud, R., Wiebicke, M., Pinzon, G., Couture, C., Hurley, R. C., Caulk, R., Caillerie, D., Matsushima, T., Bésuelle, P., Bertoni, F., Arnaud, T., Ortega Laborin, A., Rorato, R., Sun, Y., Tengattini, A., Okubadejo, O., Colliat, J.-B., Saadatfar, M., Garcia, F. E., Papazoglou, C., Vego, I., Brisard, S., Dijkstra, J. \& Birmpilis, G. (2020). SPAM: software for practical analysis of materials. J. Open Source Softw. 5, No. 51, 2286, https://doi.org/10.21105/joss. 02286

Stoss, K. \& Valk, J. (1979). Uses and limitations of ground freezing with liquid nitrogen. Engng Geol. 3, No. 1-4, 485-494.

Sutterer, K. G., Frost, J. D. \& Chameau, J. L. A. (1996). Polymer impregnation to assist undisturbed sampling of cohesionless soils. J. Geotech. Engng 122, No. 3, 209-215.

Vaid, Y. and Negussey, D. (1988). Preparation of reconstituted sand specimens. In Advanced triaxial testing of soil and rock (eds R. Donaghe, R. Chaney and M. Silver), pp. 405-417. West Conshohocken, PA, USA: ASTM International.

Vaid, Y. P. \& Sivathayalan, S. (1996). Errors in estimates of void ratio of laboratory sand specimens. Can. Geotech. J. 33, No. 6, 1017-1020.

Vaid, Y. P. \& Sivathayalan, S. (2000). Fundamental factors affecting liquefaction susceptibility of sands. Can. Geotech. J. 37, No. 3, 592-606.

Vaid, Y. P. P., Sivathayalan, S. \& Stedman, D. (1999). Influence of specimen-reconstituting method on the undrained response of sand. Geotech. Test. J. 22, No. 3, 187.

van der Walt, S., Schönberger, J. L., Nunez-Iglesias, J., Boulogne, F., Warner, J. D., Yager, N. \& the scikit-image contributors (2014). Scikit-image: image processing in Python. PeerJ 2, e453, https://doi.org/10.7717/peerj.453.

Van Rossum, G. \& Drake, F. L. (2009). Python 3 reference manual. Scotts Valley, CA, USA: CreateSpace.

Viggiani, G. \& Tengattini, A. (2019). Recent developments in laboratory testing of geomaterials with emphasis on imaging. In Proceedings of the XVII ECSMGE: geotechnical engineering foundation of the future (eds H. Sigursteinsson, S. Erlingsson and B. Bessason), pp. 109-135. Reykjavik, Iceland: Icelandic Geotechnical Society.

Wanatowski, D. \& Chu, J. (2008). Effect of specimen preparation method on the stress-strain behavior of sand in plane-strain compression tests. Geotech. Test. J. 31, No. 4, 1-13. 
Wiebicke, M. (2020). Experimental analysis of the evolution of fabric in granular soils upon monotonic loading and load reversals. $\mathrm{PhD}$ thesis, Institute for Geotechnics, Technical University of Dresden, Dresden, Germany.

Wiebicke, M., Andò, E., Herle, I. \& Viggiani, G. (2017). On the metrology of interparticle contacts in sand from X-ray tomography images. Meas. Sci. Technol. 28, No. 12, article 124007.

Wiebicke, M., Andò, E., Smilauer, V., Herle, I. \& Viggiani, G. (2019). A benchmark strategy for the experimental measurement of contact fabric. Granular Matter 21, No. 3, article 54.

Yamamuro, J. A. \& Wood, F. M. (2004). Effect of depositional method on the undrained behavior and microstructure of sand with silt. Soil Dyn. Earthq. Engng 24, No. 9-10, 751-760.

Yang, C. T. (2002). Boundary condition and inherent stratigraphic effects on microstructure evolution in sand specimens. $\mathrm{PhD}$ thesis, Georgia Institute of Technology, Atlanta, GA, USA.
Yoshimi, Y., Hatanaka, M. \& Oh-Oka, H. (1977). A simple method for undisturbed sand sampling by freezing. Proceedings of speciality session 2 on soil sampling, 9th international conference on soil mechanics and foundation engineering, Tokyo, Japan, pp. 23-28.

Yoshimi, Y., Hatanaka, M. \& Oh-Oka, H. (1978). Undisturbed sampling of saturated sands by freezing. Soils Found. 18, No. 3, $59-73$.

Yoshimi, Y., Tokimatsu, K., Kaneko, O. \& Makihara, Y. (1984). Undrained cyclic shear strength of a dense Niigata sand. Soils Found. 24, No. 4, 131-145.

Yushkevich, P. A., Piven, J., Hazlett, H. C., Smith, R. G., Ho, S., Gee, J. C. \& Gerig, G. (2006). User-guided 3D active contour segmentation of anatomical structures: significantly improved efficiency and reliability. Neuroimage 31, No. 3, $1116-1128$. 